\title{
Nonlinear Coupling Characteristics Analysis of Integrated System of Electromagnetic Brake and Frictional Brake of Car
}

\author{
Ren He and Donghai Hu \\ School of Automobile and Traffic Engineering, Jiangsu University, Zhenjiang 212013, China \\ Correspondence should be addressed to Donghai Hu; jsherohu@126.com
}

Received 2 February 2015; Revised 29 April 2015; Accepted 3 May 2015

Academic Editor: Francesco Braghin

Copyright ( 2015 R. He and D. Hu. This is an open access article distributed under the Creative Commons Attribution License, which permits unrestricted use, distribution, and reproduction in any medium, provided the original work is properly cited.

\begin{abstract}
Since theoretical guidance is lacking in the design and control of the integrated system of electromagnetic brake and frictional brake, this paper aims to solve this problem and explores the nonlinear coupling characteristics and dynamic characteristics of the integrated system of electromagnetic brake and frictional brake. This paper uses the power bond graph method to establish nonlinear coupling mathematical model of the integrated system of electromagnetic brake and frictional brake and conducts the contrastive analysis on the dynamic characteristics based on this mathematical model. Meanwhile, the accuracy of the nonlinear coupling mathematical model proposed above is verified on the hardware in the loop simulation platform, and nonlinear coupling characteristics of the integrated system are also analyzed through experiments.
\end{abstract}

\section{Introduction}

The function of automotive active braking control system has been constantly improved since the 1990s. In order to eliminate the defects of the function, the active braking control system has developed rapidly in the direction of integration and intelligence $[1,2]$ while the brake-by-wire system might develop in the direction of active braking control system in the future. As a transitional product between the traditional brake system and brake-by-wire system, electronic hydraulic brake has attracted much attention from the automobile component manufacturers $[3,4]$. EHB has eliminated the coupled relationship between the brake pedal and the driver without vacuum booster [5] which makes friction brake more simple and compact $[6,7]$. EHB can also control braking force of each wheel separately and realize the maximization of the braking energy recovery easily. As a result, EHB is of special application value for electric vehicles [8].

Though these advantages of EHB are obvious, its study might be just in its infancy and there are still a lot of problems to be remedied. The EHB's dynamic characteristics are closely related to gas pressure of the accumulator since the EHB applies the accumulator as the main pressure source. The large gas pressure of the accumulator makes the quick brake response possible, but it needs further improvement in precision control [9]. Though the high-speed solenoid valve of traditional $A B S$ can maintain a higher reliability under the emergency brake, EHB's constant braking under the traditional brake system would inevitably result in lower reliability. Compared with the traditional brake system, EHB has realized electronic control, but its nature has not changed as a friction brake. Friction brake might produce poisonous dust particles and harsh braking noise, because disc brake still uses the frictional force between the friction block and the brake disc to realize braking when the vehicle is running on the crowded road [10].

In order to address these problems, the electromagnetic brake might be an optimal alternative. The EMB is a kind of noncontact brake with faster response and easier control [11]. A calculation method of the magnetic induction intensity and braking torque of electromagnetic brake was put forward and the synovial variable structure controller was designed and antilock control experimental study was carried on in a miniature model of the EMB [12]. However, the EMB also has some disadvantages: EMB requires a larger exciting current, lacks failure safety mechanisms, and has a lower braking efficiency at low speeds. Considering advantages and disadvantages of these two brakes, some experts proposed 
that EMB and EHB be integrated to establish an integrated system of electromagnetic brake and frictional brake. In the bus equipped with the integrated system (ISEFB), the synovial nonlinear variable structure controller was developed by Sohel Anwar for the ABS/ESP control. Experimental results showed that the ISEFB had good braking performance on roads of low adhesion coefficient $[13,14]$.

In this paper, both the research purpose and the research significance of this integrated system of electromagnetic brake and frictional brake are explained systematically. Meanwhile, this paper also provides the theoretical foundation for the research on design and control of ISEFB through analyzing its nonlinear coupling characteristics and dynamic characteristics. In the second part, nonlinear coupling mathematical model related to ISEFB is established and the accuracy of the mathematical model and nonlinear coupling characteristics of ISEFB are analyzed and verified on the hardware in the loop simulation platform, respectively. Dynamic characteristics of ISEFB are discussed in the third part. In the case of emergency brake, the influences of the integrated system of electromagnetic brake and frictional brake on the design and the control strategy are analyzed in the last part.

\section{Modeling and Analysis of Nonlinear Coupling Characteristics of ISEFB}

\subsection{Nonlinear Mathematical Model of EHB}

2.1.1. Bladder Accumulator. The bladder accumulator stores high-pressure braking fluid from the hydraulic pump and then conveys the fluid to the disc brake. When the bladder accumulator is connected to the hydraulic brake system, a certain length is available at the entrance of connecting pipeline. Because the connecting pipeline has a significant influence on the dynamic characteristics of the bladder accumulator, it is an indispensable part of the bladder accumulator. High-pressure braking fluid flows into the accumulator when the inlet pressure of connecting pipeline is higher than the gas pressure of bladder accumulator. The equation of the fluid pressure balance in the connecting pipeline can be written as

$$
P_{P}-P_{A}=R_{A} Q_{A}+L_{A} \frac{d Q_{A}}{d t}
$$

where $P_{P}, P_{A}, Q_{A}, R_{A}$, and $L_{A}$ represent working pressure of the hydraulic pump, gas pressure of the bladder accumulator, actual flow of the bladder accumulator, fluid resistance, and hydraulic inductance of the bladder accumulator, respectively.

Flow continuity equation in the connecting pipeline can be described as

$$
Q_{A}=C_{A} \frac{d P_{A}}{d t},
$$

where $C_{A}$ is hydraulic capacitance of the bladder accumulator.
If the liquid flow direction is positive in flowing into the bladder accumulator, the hydraulic capacitance of the bladder accumulator can be expressed as

$$
C_{A}=\frac{V_{A 0}}{n P_{A 0}}
$$

where $P_{A 0}$ and $V_{A 0}$ are the initial stress and volume of the accumulator, respectively. $n$ is the polytropic process index of the gas of which $n=1$ in isothermal process and $n=1.4$ in the adiabatic process.

2.1.2. High-Speed Solenoid Valve. High-speed solenoid valve, a primary control component of $\mathrm{EHB}$, has two working conditions: open (oil outlet connected to drain port) and shut (oil outlet connected to oil inlet) [15]. The flow continuity equation of oil inlet and oil outlet can be expressed as

$$
\begin{gathered}
Q_{\text {in }}=C_{d} A_{\text {in }} \sqrt{\frac{2\left(P_{\text {in }}-P_{\mathrm{val}}\right)}{\rho}} \operatorname{sgn}\left(P_{\mathrm{in}}-P_{\mathrm{val}}\right), \\
Q_{\text {out }}=C_{d} A_{\text {out }} \sqrt{\frac{2\left(P_{\mathrm{val}}-P_{\mathrm{out}}\right)}{\rho}} \operatorname{sgn}\left(P_{\mathrm{val}}-P_{\text {out }}\right) .
\end{gathered}
$$

where $C_{d}$ is discharge coefficient and in the turbulent state $C_{d}=0.61 . P_{\text {in }}, P_{\text {out }}$, and $P_{\text {val }}$ represent hydraulic pressure at oil inlet, outlet, and hydraulic chamber of high-speed solenoid valve, respectively. $A_{\text {in }}$ and $A_{\text {out }}$ are sectional area at oil inlet and outlet.

Since oil pressure is affected by oil compressibility in hydraulic cavity, the pressure balance equation can be obtained as

$$
P_{\text {out }}=\frac{K_{O}}{V_{V}} \int\left(Q_{\text {in }}-Q_{\text {out }}\right) d t+P_{\text {val }} \text {, }
$$

where $K_{O}$ and $V_{V}$ represent bulk modulus of elasticity of the brake oil and hydraulic chamber volume of high-speed solenoid valve, respectively.

2.1.3. Braking Pipe. The pressure of brake cylinder changes during braking as the pressure of braking pipe changes. Lumped parameter method is a main method used for establishing the mathematical model for dynamic characteristics of braking pipe. In this method, the braking fluid in braking pipe is treated as an integral whole, where pressure, velocity, and other physical quantities are considered to be the same everywhere in the whole line and the influence of liquid viscosity is neglected. In the case of laminar flow in braking pipe, the pressure balance equation and flow continuity equation for the braking pipe can be expressed as

$$
\begin{aligned}
P_{\mathrm{hi}} & =P_{\mathrm{ho}}+R_{H} Q_{\mathrm{ho}}+L_{H} \frac{d Q_{\mathrm{ho}}}{d t}, \\
Q_{\mathrm{hi}} & =Q_{\mathrm{ho}}+C_{H} \frac{d P_{\mathrm{ho}}}{d t}
\end{aligned}
$$

where $R_{H}, L_{H}$, and $C_{H}$ are fluid resistance, hydraulic inductance, and hydraulic capacitance of the braking pipe, 
respectively. $P_{\text {hi }}$ and $P_{\text {ho }}$ are pressure at oil inlet and outlet of the braking pipe. $Q_{\mathrm{hi}}$ and $Q_{\mathrm{ho}}$ are flux at oil inlet and outlet of the braking pipe.

2.1.4. Brake Cylinder. The pressurization process of brake cylinder can be divided into two phases. One is the idle motion stage in which the air gap is eliminated between braking block and brake disc. And the other is the stable pressurization stage in which the braking lining and brake disc deformation work [16]. The piston of brake cylinder first overcomes the frictional force before moving up and down during the idle motion stage. In this stage, high-pressure braking fluid from the bladder accumulator is only employed to balance all kinds of resistance in the process of piston movement until air gap disappears. Without considering the compressibility of brake fluid, the flow continuity equation of brake cylinder during idle motion stage can be expressed as

$$
Q_{C}=A_{P} \frac{d X_{\text {piston }}}{d t}
$$

where $A_{P}, X_{\text {piston, }}$ and $Q_{C}$ represent sectional area and displacement of the piston and flux of the braking cylinder, respectively.

The force situation and the piston movement of disc brake can be expressed approximately by quality-spring-damper system. If the initial displacement of piston is zero, there are

$$
\begin{aligned}
P_{C} A_{P}= & M_{P} \frac{d^{2} X_{\text {piston }}}{d t^{2}}+B \frac{d X_{\text {piston }}}{d t} \\
& +\left(K_{d}+K_{s}\right) X_{\text {piston }}
\end{aligned}
$$

where $M_{P}, B, K_{s}, K_{d}$, and $P_{C}$ represent weight of the piston, the damping coefficient of the piston moving in the braking cylinder, stiffness of the return spring, stiffness of the spring of brake disc, and pressure in the braking cylinder, respectively.

Oil compressibility and elastic deformation of brake disc and brake cylinder are treated as main factors in analyzing the flow characteristics of brake cylinder because the motion displacement of piston is less after the idle motion stage. If the flow direction of brake cylinder fluid is positive, the flow continuity equation of brake cylinder can be expressed as

$$
Q_{C}=\frac{V_{C}}{K_{C}} \frac{d P_{C}}{d t},
$$

where $V_{C}$ is volume of the braking cylinder. $K_{C}$ is the equivalent bulk modulus of elasticity the braking cylinder.

Considering the stiffness of brake disc, the formula of $K_{C}$ can be expressed as

$$
\frac{1}{K_{C}}=\frac{1}{K_{O}}+\frac{A_{P}^{2}}{K_{p} V_{C}} .
$$

According to the pressure of brake cylinder, the braking torque of disc brake can be calculated as follows:

$$
T_{h}=2 \eta R_{m} P_{C} A_{P},
$$

where $\eta$ is the friction coefficient between the braking block and brake disc. $R_{m}$ is the effective radius of brake disc.
2.2. Nonlinear Mathematical Model of EMB. Magnetomotive force (MMF) of EMB is composed of eddy current MMFs and excitation MMFs. Because both eddy current MMFs and excitation MMFs are AC excited, the analysis of EMB's magnetic circuit becomes complicated [17]. Therefore, the magnetic circuit of electromagnetic brake in this paper is assumed as static magnetic circuit and an equivalent DC magnetic circuit. The simplified equation of magnetic circuit could be expressed as

$$
M-M_{e}=H l_{g}+H_{1} \Delta_{h}+H_{2} l,
$$

where $M$ is the excitation MMFs and $M=N I . M_{e}$ is the eddy current MMFs and $M_{e}=\sqrt{2} \Phi \omega \Delta_{h} / 8 \pi \rho$. $H$ is magnetic field intensity in the air gap and $H=\Phi / S_{p} \mu_{0} . \Delta_{h}$ is the depth of the skin and $\Delta_{h}=\sqrt{2 \rho / \omega \mu_{0} \mu_{r}} . l_{g}, H_{2}, l, H_{1}, N$, $I, \Phi, S_{p}, \mu_{0}, \mu_{r}, \omega$, and $\rho$ represent length of the air gap, magnetic field intensity of the iron core, length of the iron core, magnetic field intensity in the brake disc, coil turns, the exciting current, the magnetic flux, sectional area of the magnetic circuit, vacuum magnetic permeability of brake disc, relative permeability of brake disc, rotation speed, and resistivity of the brake disc, respectively.

The brake disc is mainly made of gray cast iron, and the main material of iron core is industrial pure iron. Both materials are soft magnetic materials. The relationship between magnetic induction intensity and applied magnetic field strength is saturation nonlinear as shown in Figure 1. Because saturation nonlinearity of soft magnetic materials is important to the performance of brake disc, it cannot simply be linearized during building the mathematical model of EMB.

Saturation nonlinearity of soft magnetic materials is expressed by the power series functions in this paper. And the least squares method is used to determine the coefficients and obtain magnetization curves of soft magnetic materials. Consider

$$
\begin{aligned}
& H_{1}=f_{1}\left(\Phi_{1}\right)=c_{1} \Phi_{1}+c_{2} \Phi_{1}^{3}, \\
& H_{2}=f_{2}\left(\Phi_{2}\right)=c_{3} \Phi_{2}+c_{4} \Phi_{2}^{3},
\end{aligned}
$$

where $H_{1}$ and $H_{2}$ represent magnetic field strength of iron core and brake disc, respectively. $\Phi_{1}, \Phi_{2}$ are magnetic flux of the brake disc and the iron core. $c_{1}, c_{2}, c_{3}, c_{4}$ are the fitting coefficient.

Assuming that exciting magnetic field, air gap magnetic field, and brake discs magnetic field have the same crosssectional area, the nonlinear equation of magnetic flux can be expressed as

$$
N I-\frac{\sqrt{2} \Phi \omega \Delta_{h}}{8 \pi \rho}=\frac{\Phi}{S_{p} \mu_{0}} l_{g}+f_{1}(\Phi) \cdot \Delta_{h}+f_{2}(\Phi) \cdot l .
$$

Nonlinear equation (14) could be solved by dichotomy to get the magnetic flux of magnetic circuit. The formula of calculating the electromagnetic braking torque can be expressed as follows $[18,19]$ :

$$
T_{e}=K_{e} \Delta_{h} \omega \Phi^{2}
$$




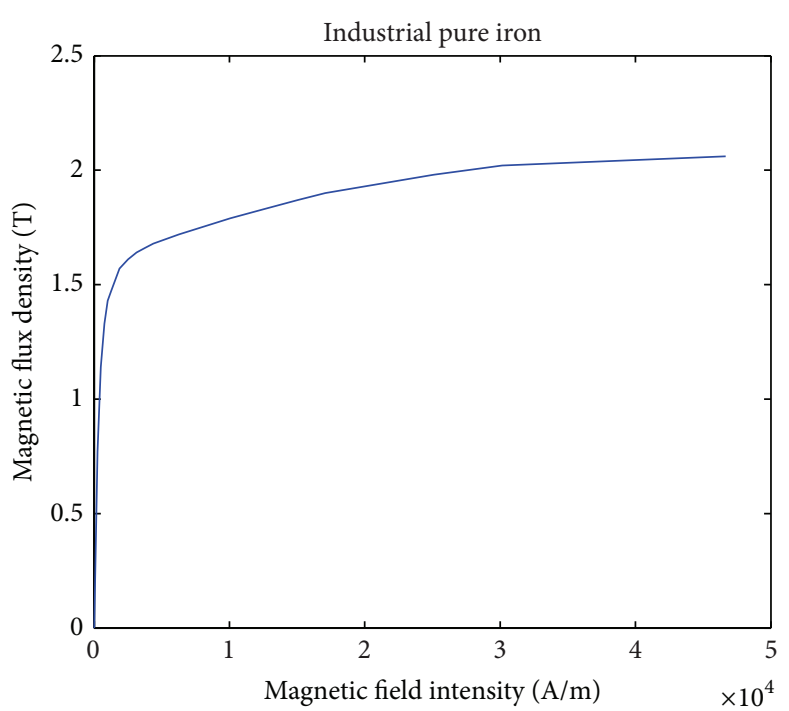

(a)

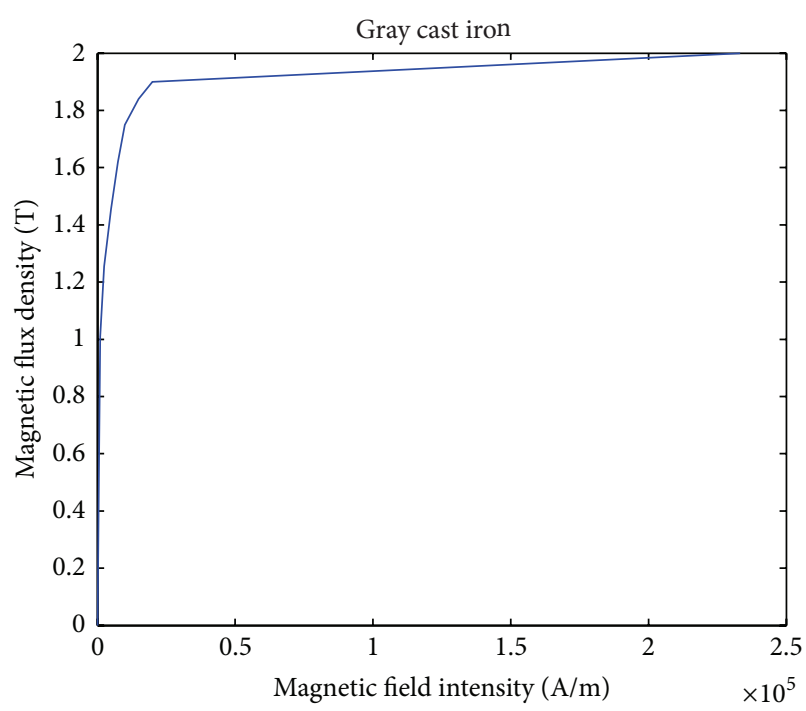

(b)

FIGURE 1: Magnetization curve of soft magnetic materials.

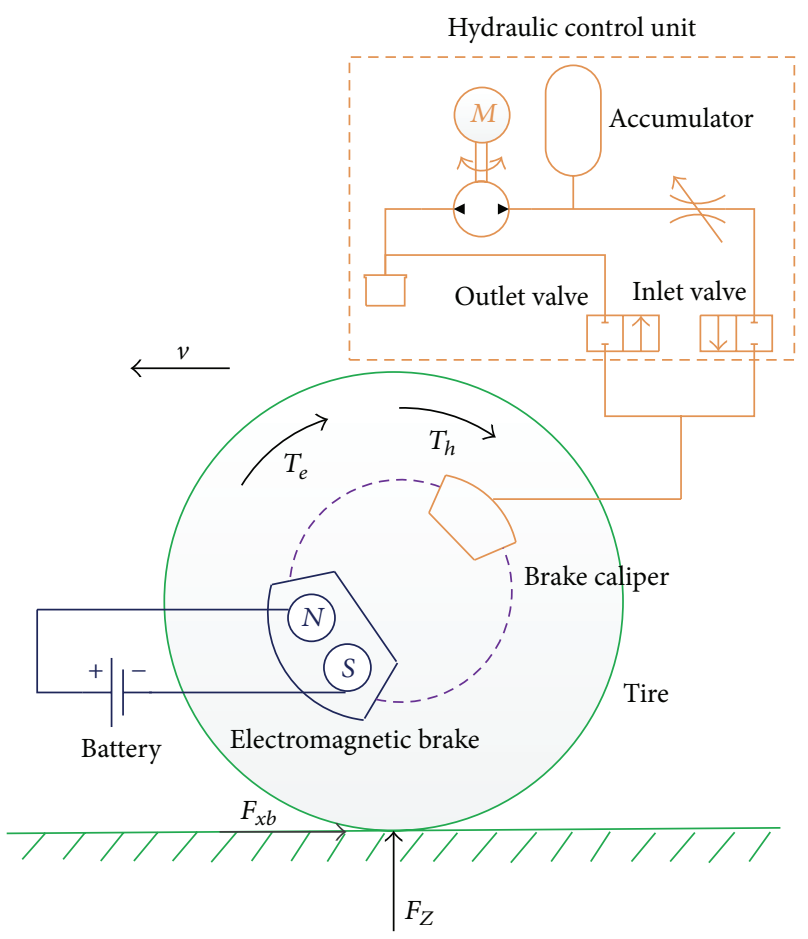

Figure 2: Single wheel brake model of the integrated system of electromagnetic brake and frictional brake.

where $K_{e}$ is the gain coefficient of electromagnetic brake, and $K_{e}=N_{p} k S_{p} / 8 \pi \rho . N_{p}$ is the number of pole pairs. $k$ is the gain effective area.

2.3. Single Wheel Brake Model. Single wheel brake model is widely used in the study of the active braking control as showed in Figure 2. This model is mainly used for analysis of vehicle longitudinal dynamics characteristics without considering the influence of the kinetics of horizontal pendulum and pitching [20]. Vertical force between tire and ground is influenced by car quality and load transfer. In the coupled nonlinear mathematical model of ISEFB, the longitudinal braking force $F_{x b}$ controlled by slip ratio is longitudinal force of wheels roughly; $T_{h}$ is hydraulic braking torque; and $T_{e}$ is electromagnetic braking torque on wheels [21, 22]. The wheel dynamics model can be expressed as

$$
\begin{aligned}
& \dot{\omega}_{\text {wheel }}=\frac{1}{J_{W}}\left[F_{Z} \cdot \mu(s) \cdot r-T_{e}-T_{h}\right], \\
& \dot{v}_{\text {vehicle }}=-\frac{1}{M_{V}} F_{Z} \cdot \mu(s),
\end{aligned}
$$

where $\omega_{\text {wheel }}$ and $v_{\text {vehicle }}$ represent the angular velocity of the wheels and the speed of the vehicle, respectively. $J_{W}$ is the rotational inertia of the wheel. $M_{V}$ is a quarter of sprung mass of the vehicle. $s$ is the wheel slip ratio and $s=\left(v_{\text {vehicle }}-\right.$ $\left.\omega_{\text {wheel }} r\right) / v_{\text {vehicle }} . r$ is the rolling radius of wheel.

$\mu(s)$ is the function of attachment coefficient changes with slip ratio. The relationship between adhesion coefficient and the slip ratio generally could be simulated using the double linear model. Consider

$$
\begin{aligned}
& \mu(s)=\frac{\mu_{h}}{s_{\mathrm{opt}}} s \quad s<s_{\mathrm{opt}}, \\
& \mu(s)=\frac{\mu_{h}-\mu_{g} s_{\mathrm{opt}}}{1-s_{\mathrm{opt}}}-\frac{\mu_{h}-\mu_{g}}{1-s_{\mathrm{opt}}} s \quad s>s_{\mathrm{opt}},
\end{aligned}
$$

where $s_{\text {opt }}$ is the optimal wheel slip. $\mu_{h}$ is the peak attachment coefficient. $\mu_{g}$ is the sliding attachment coefficient.

2.4. Coupled Nonlinear Mathematical Model of ISEFB. Considering nonlinear and coupling characteristics of the integrated brake system, power bond graph method is used 
Hydraulic control unit

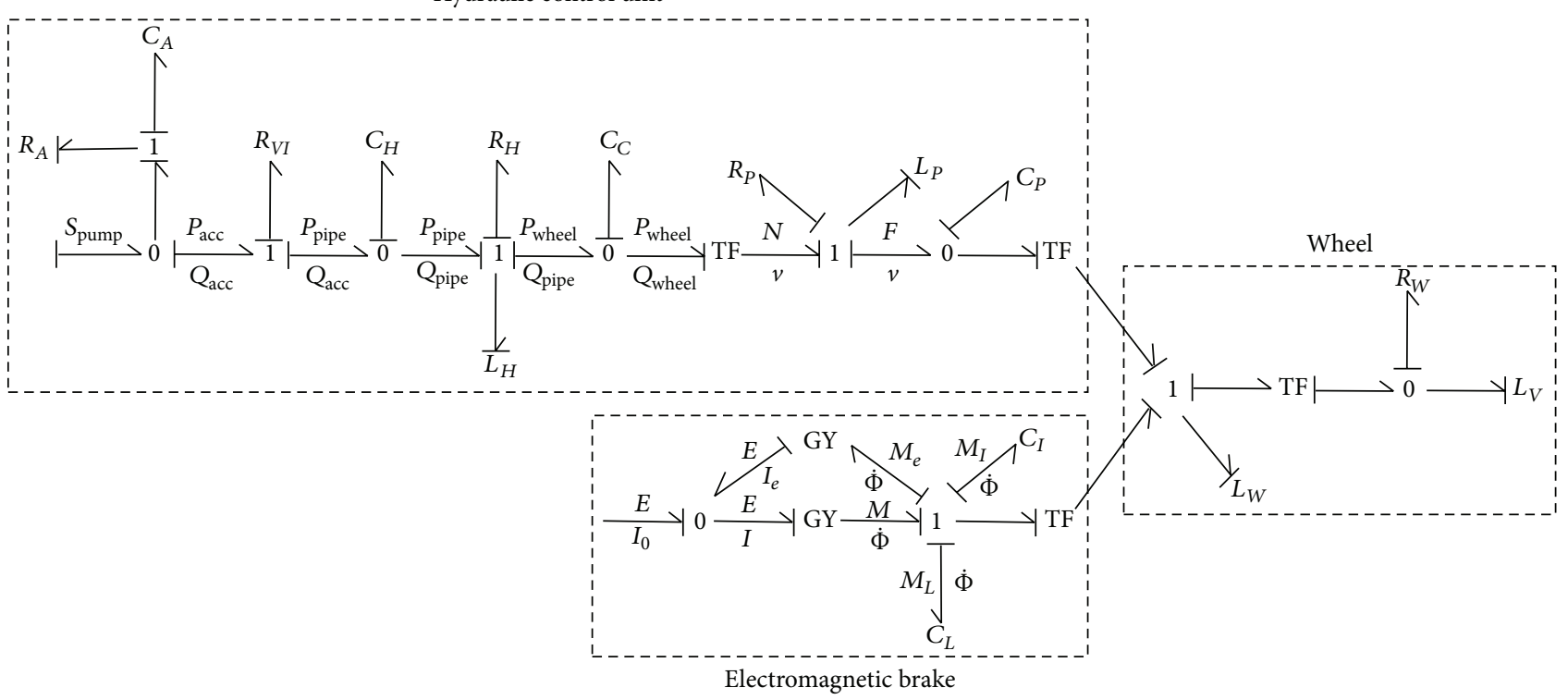

FIGURE 3: Power bond graph of the ISEFB in brake booster stage.

to establish the nonlinear coupling mathematical model. Power bond graph of ISEFB is shown in Figure 3 when the pressure is increasing. Because power bond graphs are similar when the pressure remains unchanged or decreases, they are excluded in this paper. When the pressure remains unchanged, decreases, and increases, the dynamic equations of ISEFB can be obtained by constructing their power bond graphs.

In the case of increasing pressure, the dynamic equation of ISEFB is as follows:

$$
\begin{aligned}
& \dot{V}_{\text {acc }}=\frac{V_{\text {acc }}}{C_{A}\left(R_{V I}+R_{A}\right)}-\frac{V_{\text {pipe }}}{C_{A}\left(R_{V I}+R_{A}\right)}, \\
& \dot{V}_{\text {pipe }}=\frac{V_{\text {acc }}}{C_{A}\left(R_{V I}+R_{A}\right)}-\frac{V_{\text {pipe }}}{C_{A}\left(R_{V I}+R_{A}\right)}-\frac{P_{\text {pipe }}}{L_{H}}, \\
& \dot{P}_{\text {pipe }}=\frac{V_{\text {pipe }}}{C_{H}}-\frac{V_{\text {cylinder }}}{C_{C}}-R_{H} \frac{P_{\text {pipe }}}{L_{H}}, \\
& \dot{V}_{\text {cylinder }}=\frac{P_{\text {pipe }}}{L_{H}}-v_{\text {piston }} A_{P}, \\
& \dot{v}_{\text {piston }}=\frac{1}{M_{P}}\left[\frac{V_{\text {cylinder }}}{C_{C}} A_{P}-B v_{\text {piston }}\right. \\
& \left.-\left(K_{d}+K_{s}\right) X_{\text {piston }}\right] \\
& \dot{X}_{\text {piston }}=v_{\text {piston }}, \\
& \dot{\omega}_{\text {wheel }}=\frac{1}{J_{W}}\left[F_{Z} \cdot \mu(s) \cdot r-2 \eta R_{m} \frac{V_{\text {cylinder }}}{C_{C}} A_{P}\right. \\
& \left.K_{e} \Delta_{h} \omega_{\text {wheel }} \Phi^{2}\right],
\end{aligned}
$$

$$
\begin{aligned}
& \dot{v}_{\text {vehicle }}=-\frac{1}{M_{V}} F_{Z} \cdot \mu(s), \\
& \dot{\Phi}=\frac{\sqrt{2}}{2} \cdot B \cdot S_{p} \cdot \omega_{\text {wheel }} .
\end{aligned}
$$

In the case of unchanged pressure, the dynamic equation of ISEFB is as follows:

$$
\begin{aligned}
& \dot{\omega}_{\text {wheel }} \\
& =\frac{1}{J_{W}}\left[F_{Z} \cdot \mu(s) \cdot r-2 \eta R_{m} P_{C} A_{P}-K_{e} \Delta_{h} \omega_{\text {wheel }} \Phi^{2}\right], \\
& \dot{v}_{\text {vehicle }}=\frac{1}{M_{V}}\left[F_{Z} \cdot \mu(s)+F_{f}+F_{W}\right], \\
& \dot{\Phi}=\frac{\sqrt{2}}{2} \cdot B \cdot S_{p} \cdot \omega_{\text {wheel }} .
\end{aligned}
$$

In the case of decreasing pressure, the dynamic equation of ISEFB is as follows:

$$
\begin{aligned}
& \dot{V}_{\text {pipe }}=\frac{P_{\text {pipe }}}{L_{H}}-\frac{V_{\text {pipe }}}{C_{A}\left(R_{V O}+R_{A}\right)}, \\
& \dot{P}_{\text {pipe }}=\frac{V_{\text {cylinder }}}{C_{C}}-\frac{V_{\text {pipe }}}{C_{H}}-R_{H} \frac{P_{\text {pipe }}}{L_{H}}, \\
& \dot{V}_{\text {cylinder }}=v_{\text {piston }} A_{P}-\frac{P_{\text {pipe }}}{L_{H}}, \\
& \dot{v}_{\text {piston }}=\frac{1}{M_{P}}\left[\frac{V_{\text {cylinder }}}{C_{C}} A_{P}-B v_{\text {piston }}\right. \\
& \left.-\left(K_{d}+K_{s}\right) X_{\text {piston }}\right],
\end{aligned}
$$




$$
\begin{aligned}
& \dot{X}_{\text {piston }}=v_{\text {piston }}, \\
& \dot{\omega}_{\text {wheel }}=\frac{1}{J_{W}}\left[F_{Z} \cdot \mu(s) \cdot r-2 \eta R_{m} \frac{V_{\text {cylinder }}}{C_{C}} A_{P}\right. \\
& \left.\quad-K_{e} \Delta_{h} \omega_{\text {wheel }} \Phi^{2}\right], \\
& \dot{v}_{\text {vehicle }}=-\frac{1}{M_{V}} F_{Z} \cdot \mu(s), \\
& \dot{\Phi}=\frac{\sqrt{2}}{2} \cdot B \cdot S_{p} \cdot \omega_{\text {wheel }},
\end{aligned}
$$

where $V_{\text {acc }}, V_{\text {pipe }}, P_{\text {pipe }}, V_{\text {cylinder }}$, and $v_{\text {piston }}$ represent the volume of accumulator, the liquid volume in the braking pipe, the liquid momentum in the braking pipe, the liquid volume of the brake braking cylinder, and the velocity of piston, respectively. $R_{V I}$ and $R_{V O}$ are the equivalent liquid resistance of the inlet valve and the outlet valve. $C_{C}$ is the hydraulic capacitance of the braking cylinder and $C_{C}=V_{W} / K_{W} . \Phi$ is the magnetic flux of the electromagnetic brake. $B$ is the magnetic induction intensity of the electromagnetic brake and $B=8 \pi \rho \mu_{0} N I /\left(8 \pi \rho l_{g}+1.5 \sqrt{2} S_{p} \mu_{0} \Delta_{h} \omega\right)$.

\subsection{Analysis of Nonlinear Coupling Characteristics of the EFIB}

2.5.1. Experimental Verification. As is shown in Figure 4, the hardware in the loop simulation platform of the electromagnetic and frictional integrated brake system is composed of the hardware part and software part. The software part includes Matlab simulation model of the integrated brake system and Labview control program. The interface test platform is based on Labview and Matlab. The hardware part includes integrated brake, sensors, drive equipment, power supply, data acquisition card, and computer. For more information about structure and control method of this hardware in the loop simulation platform refer to [23].

In order to obtain the experimental curve of braking cylinder in the process of pressure increasing and dumping, the inlet valve of EHB is first open. Then EHB starts to get pressurized until the pressure of the brake cylinder reaches the maximum and EHB maintains the same stable pressure, as shown in Figure 5. At this moment, the inlet valve is closed. Meanwhile, the outlet valve opens at $0.6 \mathrm{~s}$ and $\mathrm{EHB}$ starts to reduce the pressure. The simulation curve accords with the experimental curve. But experimental results are not as ideal as the simulation results for the possible miscalculation in the setting of brake clearance.

To obtain the experimental curve of electromagnetic braking torque, firstly drive motor, accelerate the flywheel to a certain rotating speed, and then close the drive motor. Secondly input the constant current into the electromagnetic brake. Finally use the torque speed sensor to collect the braking torque of electromagnetic brake. Approximately $5 \%$ differences are available between simulation results and experimental results as a result of difficulties in determining the air gap length of electromagnetic brake. However, the trend of the simulation curve is in good accordance with the experimental curve from Figure 6. Clearly, the braking torque of electromagnetic brake has nonlinear characteristics: electromagnetic braking torque increases rapidly at low rotational speeds, decreases at medium speeds, and will reach saturation at high speeds. However, it should be noted that when the exciting current reaches a certain degree, the air gap magnetic field of electromagnetic brake tends to be saturated and a certain braking torque recession of electromagnetic brake appears at high speeds.

2.5.2. Nonlinear Coupling Characteristics of the ISEFB. Experiment curves 1 and 2 represent the changes of electromagnetic braking torque when the pressure of brake cylinder is $0.2 \mathrm{MPa}$ and $0.4 \mathrm{MPa}$, respectively, and the current of electromagnetic brake is the same. Figure 7(a) shows that these two experimental curves of electromagnetic braking torque almost coincide with each other until $2 \mathrm{~s}$. After that, electromagnetic braking torque in experimental curve 2 decreases rapidly because the pressure of brake cylinder is higher and it causes the wheel speed to decrease rapidly as shown in Figure 7(b). First of all, this trend indicates that electromagnetic braking torque is strongly influenced by the wheel speed. By uniting formulas ((13)-(15)), conclusions can be reached that there is a nonlinear relationship between electromagnetic braking torque and wheel speed. According to formulas ((16)-(18)), because the equivalent liquid resistances of inlet valve and outlet valve are nonlinear in nature, hydraulic braking torque and EHB's input signal (duty ratio of the inlet valve and outlet valve) also have nonlinear properties. The input signal of hydraulic braking torque affects electromagnetic braking torque when $\mathrm{EMB}$ and $\mathrm{EHB}$ work together. It is obvious that the ISEFB is a coupled nonlinear system.

It can be found that hydraulic braking torque does not affect output of electromagnetic braking torque when the rotation speed of brake disc is higher than $500 \mathrm{r} / \mathrm{min}$ because the exiting saturation area is available in braking torque speed curve of electromagnetic brake by comparing Figures 6 and 7(a). In the comparison of Figures 7(a) and 7(b), it can also be found that electromagnetic braking torque drops rapidly at high speeds, but its braking torque shows no marked changes when brake disc runs at a speed less than $100 \mathrm{r} / \mathrm{min}$. Thus, in practical use, the electromagnetic brake should not be used until brake disc speed approximately reaches $100 \mathrm{r} / \mathrm{min}$.

Therefore, the following conclusions on electromagnetic brake can be reached in this paper: A nonlinear coupling relationship exists between electromagnetic brake and electric hydraulic brake only when the rotation speed of brake disc is between $500 \mathrm{r} / \mathrm{min}$ and $100 \mathrm{r} / \mathrm{min}$. In order to determine the nonlinear coupling area of the integrated brake system which involves decoupling control of the integrated brake system, it is necessary to acquire real-time wheel speed sensor signal in the actual control of ISEFB.

\section{Analysis of Dynamic Characteristics of ISEFB}

3.1. Analysis of Dynamic Characteristics of EHB. There are three main factors influencing dynamic characteristics of 


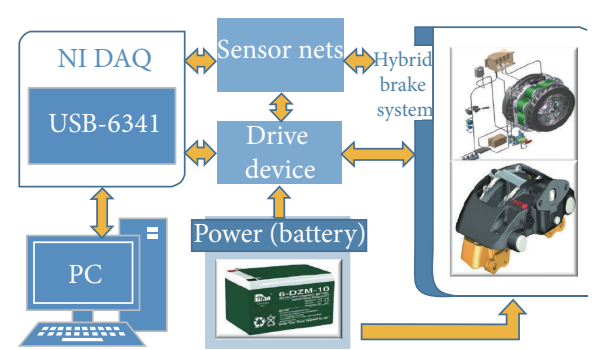

(a) Sketch for the HILS system

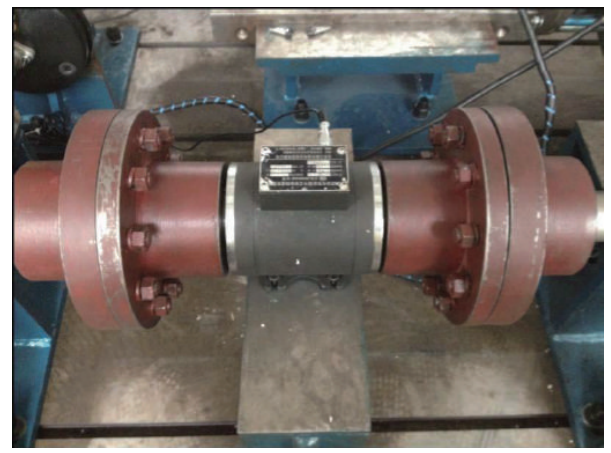

(c) Torque sensor of the testing bench

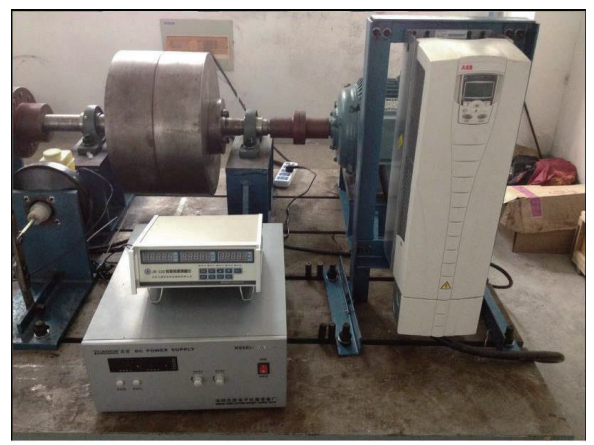

(e) Frequency transformer, instrument, and power

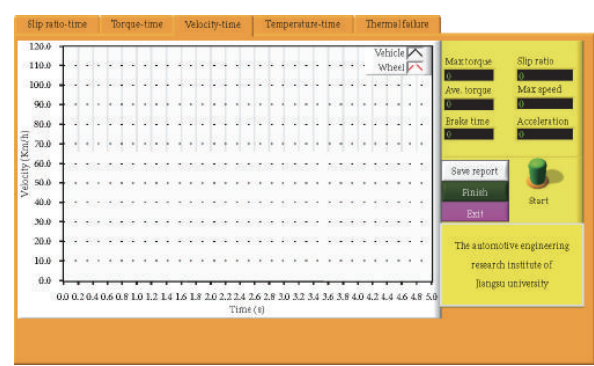

(b) Interface of the testing bench

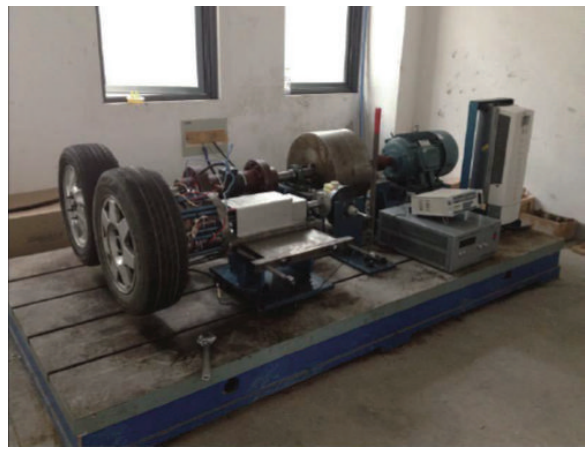

(d) Panorama of the testing bench

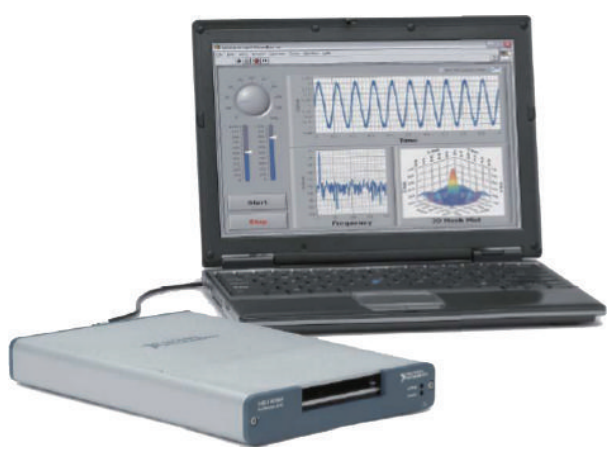

(f) Data acquisition board (USB-6341)

FIGURE 4: Hardware in the loop simulation platform of the integrated system of electromagnetic brake and frictional brake.

EHB: response time, changing rate, static error of brake cylinder pressure, and braking clearance [24, 25]. In this section, the simulation parameters are set up for analyzing these factors as follows: pressure of bladder accumulator is $12 \mathrm{MPa}$, sectional area of electromagnetic valve is $0.7 \mathrm{~mm}^{2}$, duty ratio of inlet valve and outlet valve is 0.9 , length of hard braking pipe is $5 \mathrm{~m}$, length of soft braking pipe is $0.35 \mathrm{~m}$, and inner radius of braking pipe is $3.2 \mathrm{~mm}$.

3.1.1. Response Time of Brake Cylinder Pressure. The response time of wheel cylinder pressure refers to the duration from the starting point (ECU sends a command to control the wheel cylinder pressure) to finishing point (the set point is acquired), which reflects the response speed of EHB system. In the process of obtaining response time of wheel cylinder pressure, (4) should be simplified first. Oil inlet and oil outlet of high-speed solenoid valve are equivalent to an orifice in function. The pressure equation of high-speed solenoid valve can be expressed as

$$
P_{A}-P_{C}=\frac{\rho}{2}\left(\frac{Q_{A}}{C_{d} A_{\text {in }}}\right)^{2}+\frac{\rho}{2}\left(\frac{Q_{C}}{C_{d} A_{\text {out }}}\right)^{2} .
$$

In order to simplify the analysis, dynamic characteristics of braking pipe are not considered and accumulator pressure is assumed to remain the same in the braking process because the braking pipe of EHB system has always been full of brake fluid and the response time of wheel cylinder pressure is very short. According to the flow continuity theorem $Q_{A}=Q_{C}$, the combination of (9) with (21) can be expressed as

$$
C_{d} A_{\text {in }} A_{\text {out }} \sqrt{\frac{2}{\rho\left(A_{\text {in }}^{2}+A_{\text {out }}^{2}\right)}\left(P_{A}-P_{C}\right)}=\frac{V_{C}}{K_{C}} \frac{d P_{C}}{d t} .
$$




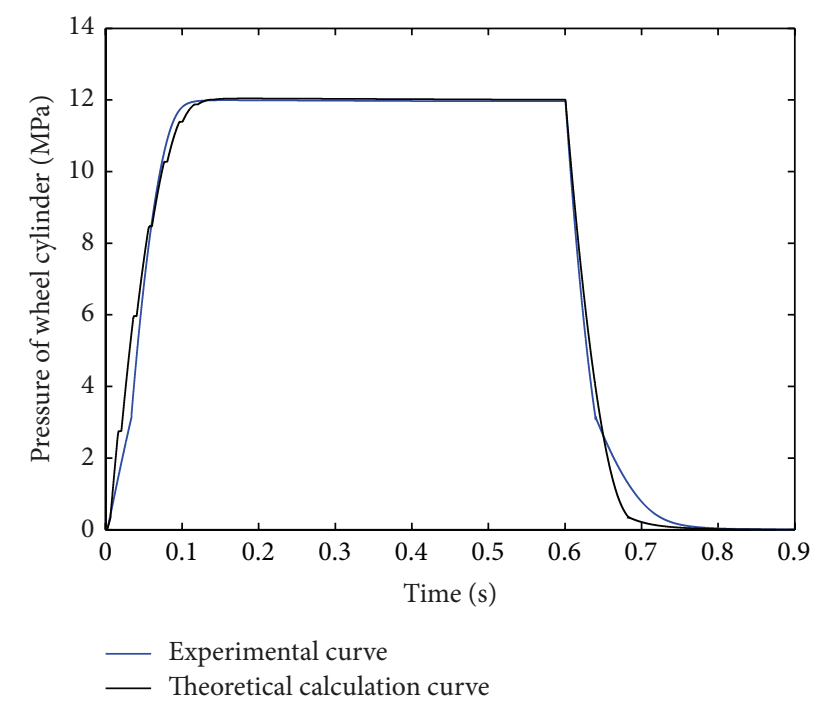

FIGURE 5: Dynamic pressure curves of electronic hydraulic brake system.

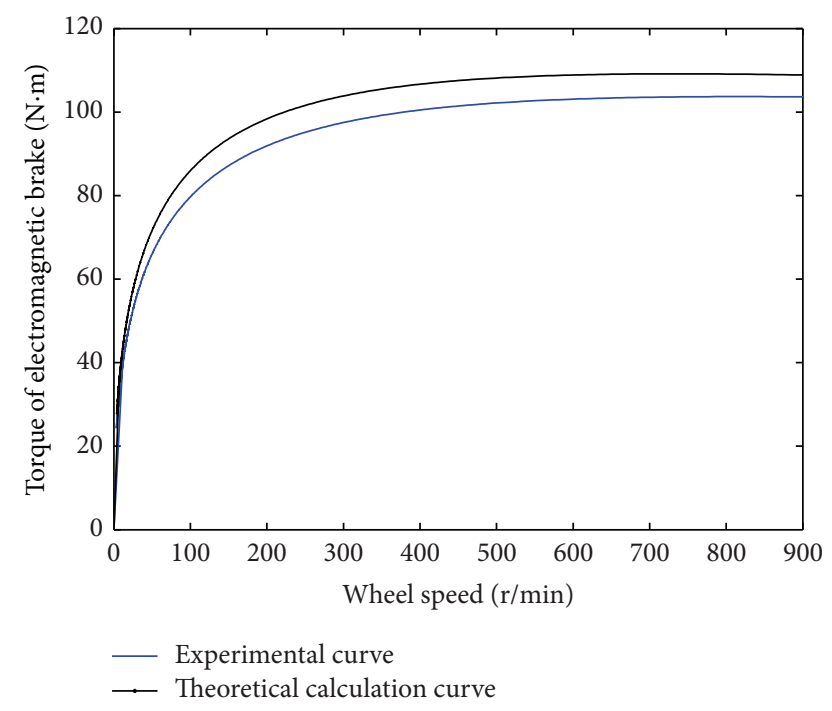

FIGURE 6: Variation curves of electromagnetic brake torque.

Then, the equation above would be transformed as

$$
=\frac{V_{C}}{K_{C} C_{d} A_{\text {in }} A_{\text {out }} \sqrt{\left(2 / \rho\left(A_{\text {in }}^{2}+A_{\text {out }}^{2}\right)\right)\left(P_{A}-P_{C}\right)}} d P_{C} .
$$

After integrating (23), equations for response time of brake wheel cylinder pressure are expressed as

$$
\begin{aligned}
t & =\frac{2 V_{C}}{K_{C} C_{d} A_{\text {in }} A_{\text {out }} \sqrt{2 / \rho\left(A_{\text {in }}^{2}+A_{\text {out }}^{2}\right)}}\left(\sqrt{P_{A}-P_{C}}\right. \\
& \left.-\sqrt{P_{A}}\right) .
\end{aligned}
$$

According to the analysis above, response time of wheel cylinder pressure is related to accumulator actual pressure and cross area of high-speed solenoid valve. At the same time, it can be clearly noticed that duty ratio of high-speed solenoid valve also affects response time of wheel cylinder pressure because it shares a similar physical mechanism to cross area of high-speed solenoid valve.

According to Figure 8, the pressure of bladder accumulator has a negligible influence on response time of brake cylinder pressure. In four simulation experiments, pressurization response time is around $0.15 \mathrm{~s}$ and depressurization response time is around $0.2 \mathrm{~s}$, which reflects that the increase of bladder accumulator pressure cannot obviously improve its response time. Compared with response time of traditional brake system, $0.3 \mathrm{~s}$, pressurization response time of EHB is improved greatly.

As is shown in Figure 9, duty ratio of high-speed solenoid valve obviously affects response time of brake cylinder pressure. Therefore, it can be used to adjust response time of brake cylinder pressure. In addition, response time of brake cylinder pressure varies slightly and accords well with that of experimental results when duty ratio ranges from 0.9 to 0.6 during the simulation experiment [26], and it is because response time of brake cylinder pressure is related to the duration when high-speed solenoid valve is opened. In the same control cycle of high-speed solenoid valve, the mechanism of adjusting response time of brake cylinder pressure by changing duty ratio is similar to that of adjusting the duration when high-speed solenoid valve is opened.

The sectional area of high-speed solenoid valve markedly affects response time of brake cylinder pressure as shown in Figure 10. Because the length and inner radius of braking pipe are limited by the small installing space and the safety factors, the range of these variations is limited. Nevertheless, several simulation experiments show that response time of brake cylinder pressure does not vary with the length and inner radius of hard braking pipe and soft braking pipe. Response time of brake cylinder pressure can be determined by the design value of sectional area of high-speed solenoid valve under the same brake clearance.

When the braking clearance increases significantly, the pressure curve and the stress curve of electronic hydraulic brake system are no longer the smooth curve but obviously divide into two segments as is shown in Figure 11. As the braking clearance increases, the time consuming in idle motion stage would obviously increase. But the trends of wheel cylinder pressure changing with time in stable pressure stage are similar under different brake clearances which shows that the brake response time of stable pressurization phase is almost the same under the condition of the identical target pressure.

3.1.2. Changing Rate of Brake Cylinder Pressure. Changing rate of wheel cylinder pressure refers to the variation of wheel cylinder pressure in a control cycle with a unit of $\mathrm{MPa} / \mathrm{T}$, which reflects the control precision of EHB system. Differential pressures are selected in the process of calculating changing rate of wheel cylinder pressure when electronic hydraulic brake is under pressurization or depressurization 


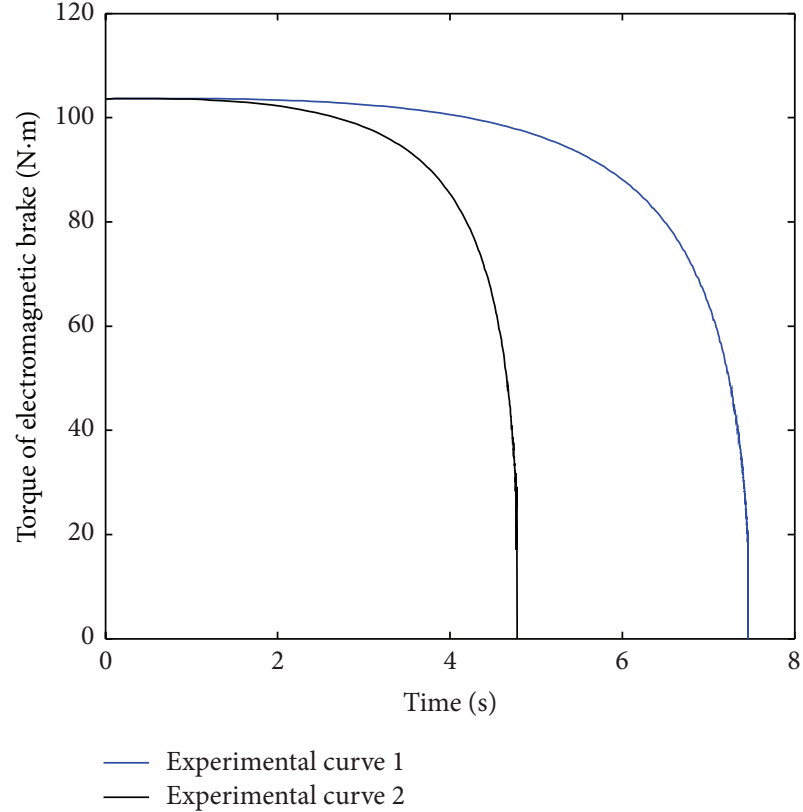

(a)

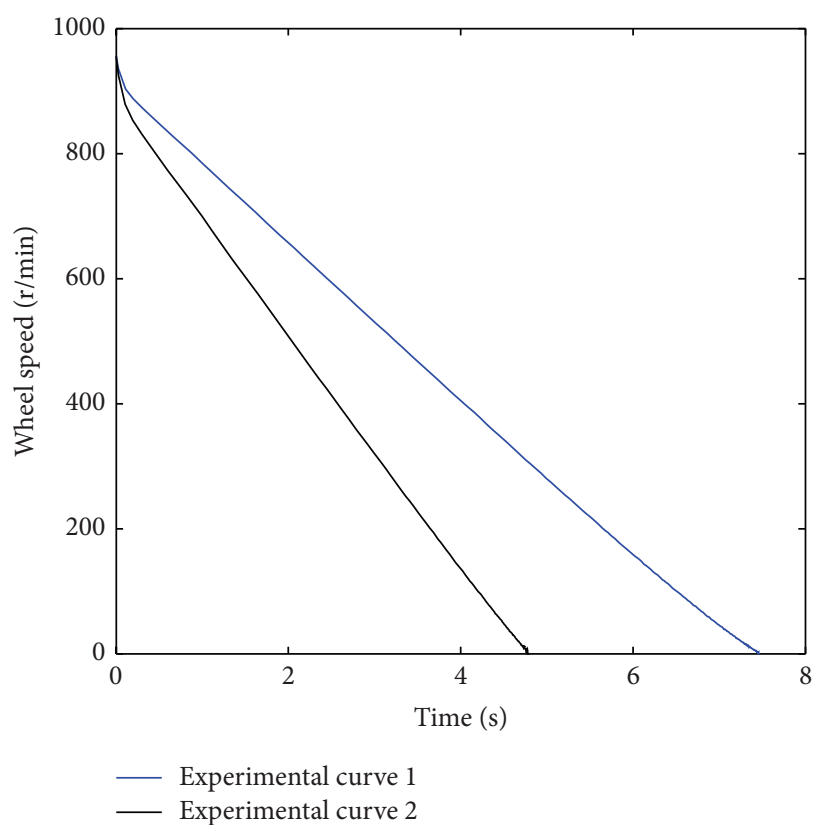

(b)

FIGURE 7: United braking curves of the integrated system of electromagnetic brake and frictional brake.

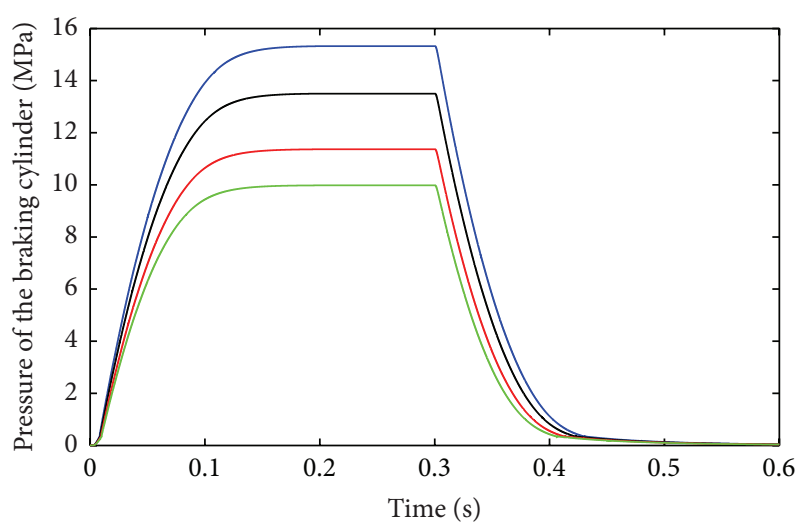

The initial pressure of accumulator $=16 \mathrm{MPa}$
The initial pressure of accumulator $=14 \mathrm{MPa}$
The initial pressure of accumulator $=12 \mathrm{MPa}$

- The initial pressure of accumulator $=10 \mathrm{MPa}$

FIGURE 8: Relationship between response time and accumulator pressure.

process. In the process of pressurization, the differential pressure from accumulator to wheel cylinder equals the sum of the differential pressure between accumulator and inlet valve and that between inlet valve and brake wheel cylinder. According to (6), the differential pressure between brake pipe and wheel cylinder is obtained as

$$
P_{\text {val }}-P_{C}=R_{H} Q_{C}+L_{H} \frac{d Q_{C}}{d t} .
$$

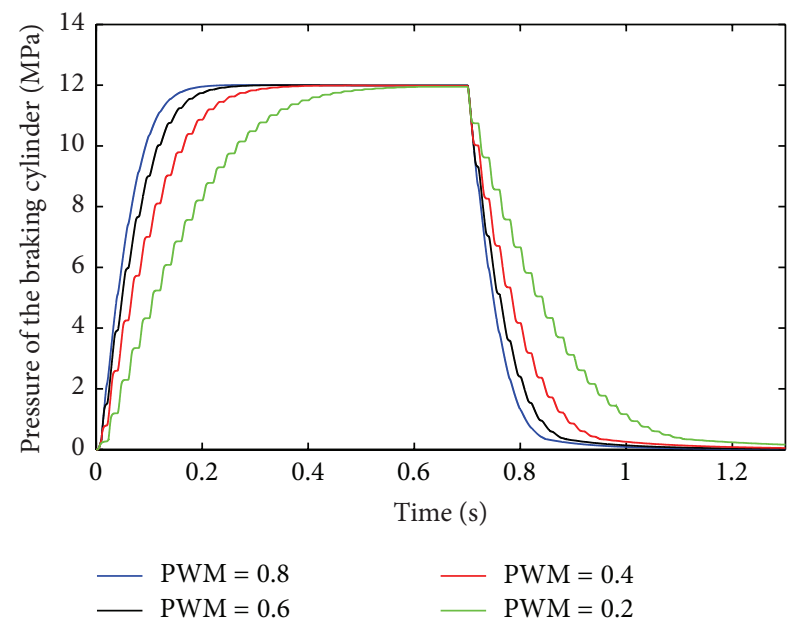

FIGURE 9: Relationship between response time and duty ratio.

By combining (21) with (25), the differential pressure between accumulator and wheel cylinder can be expressed as

$$
\begin{aligned}
P_{A}-P_{C}= & \frac{\rho}{2}\left(\frac{Q_{A}}{C_{d} A_{\text {in }}}\right)^{2}+\frac{\rho}{2}\left(\frac{Q_{C}}{C_{d} A_{\text {out }}}\right)^{2}+R_{H} Q_{C} \\
& +L_{H} \frac{d Q_{C}}{d t} .
\end{aligned}
$$

It is assumed in the braking process that change of accumulator gas pressure is constant for its slight changes in the value. Meanwhile, fluid resistance and fluid feeling of 


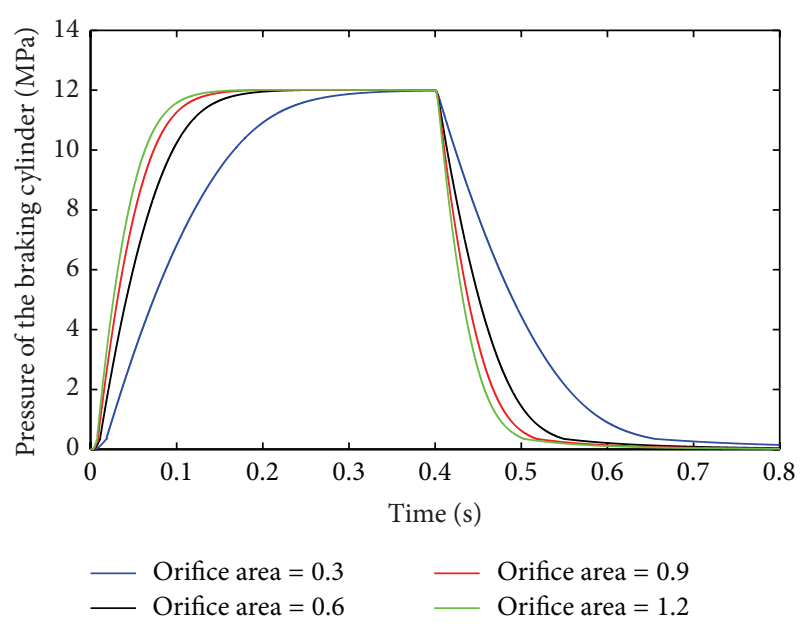

FIGURE 10: Relationship between response time and sectional area of high-speed solenoid valve.

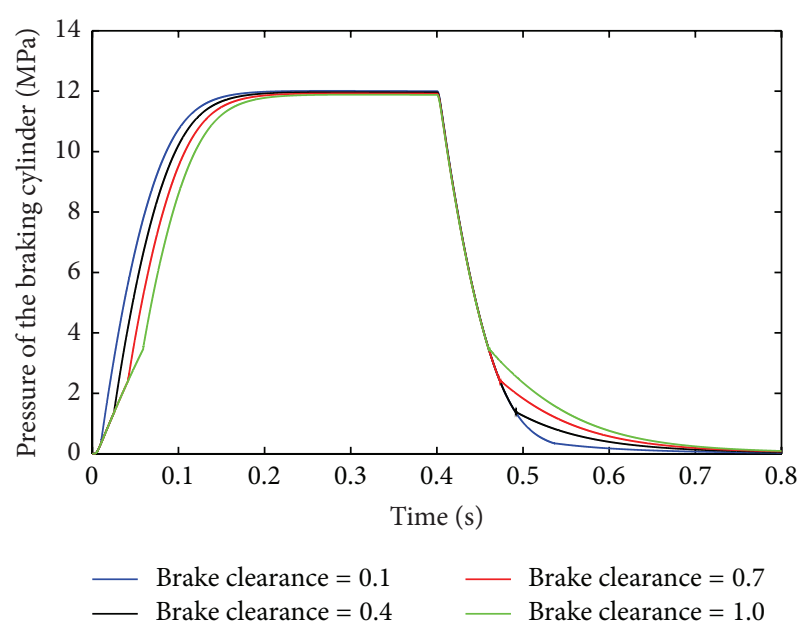

FIGURE 11: Relationship between the response time and braking clearance.

braking pipe are not treated as main factors in this process. Thus, (9) can be transformed into (26) as follows:

$$
P_{A}-P_{C}=\frac{\rho}{2}\left(\frac{1}{C_{d} A_{\text {out }}} \cdot \frac{V_{C}}{K_{C}} \cdot \frac{d P_{C}}{d t}\right)^{2} .
$$

By transforming (27), the changing rate of wheel cylinder pressure in the pressurization process is expressed as

$$
\frac{d P_{C}}{d t}=\frac{K_{C} C_{d} A_{\text {out }}}{V_{C}} \sqrt{\frac{2\left(P_{A}-P_{C}\right)}{\rho} .}
$$

The changing rate of wheel cylinder pressure in the depressurization process can be obtained as

$$
\frac{d P_{C}}{d t}=-\frac{K_{C} C_{d} A_{\text {out }}}{V_{C}} \sqrt{\frac{2 P_{C}}{\rho}} .
$$

In the initial stage, inlet valve is opened and it is closed at $0.2 \mathrm{~s}$. Duty ratio of inlet valve is 0.9 . Then EHB starts to

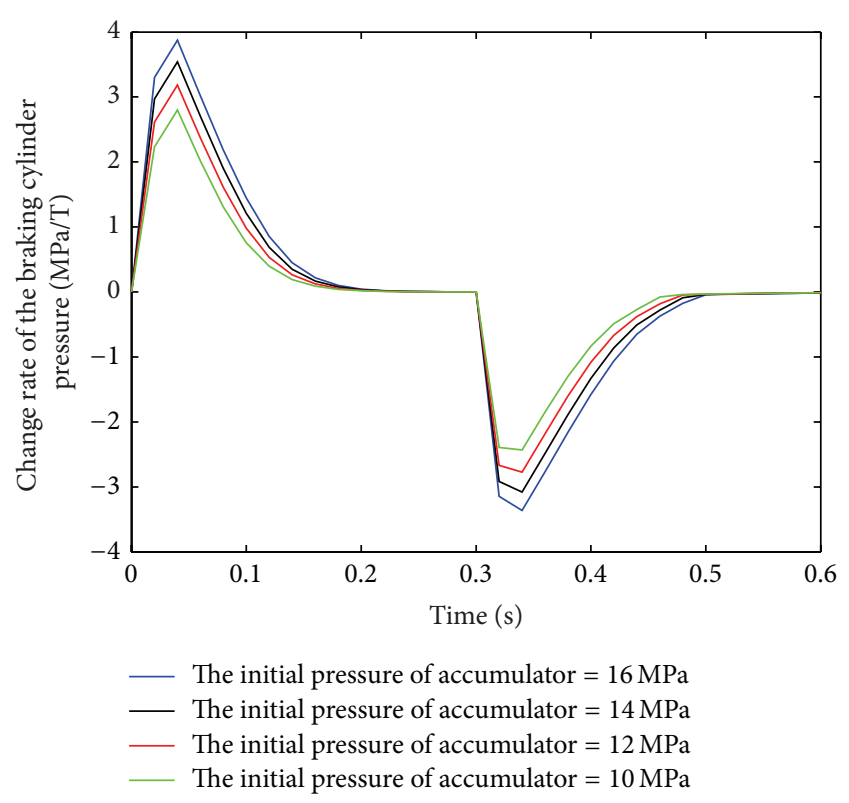

FIGURE 12: Relationship between change rate of brake cylinder pressure and accumulator pressure.

pressurize and maintains the pressure until outlet valve is opened at $0.3 \mathrm{~s}$. When reach after 3 seconds, EHB starts to reduce the pressure. In this process, change rate of brake cylinder pressure reaches the peak value and then decreases to zero, as is shown in Figure 12. The time of reaching the peak value in pressure can be similarly regarded as the finishing time of piston movement under different pressures of bladder accumulator [26]. After change rate reaches the peak value, the decrease in change rate of brake cylinder pressure results from the decrease in the differential pressure between brake cylinder pressure and bladder accumulator pressure, and it causes the continuous decrease in the flux of brake cylinder, as shown in formulas (4) and (9).

Figure 13 demonstrates that the control of change rate of brake cylinder pressure can be realized by adjusting duty ratio of high-speed solenoid valve. Measured by variations of brake cylinder pressure in a unit control cycle, the change rate of brake cylinder pressure is $1 \mathrm{MPa} / \mathrm{T}$ and duty ratio of inlet valve is 0.2 , but it is too big to meet the conventional braking requirement. Therefore, it is necessary to study the design theory of EHB to meet its specific design requirements because the structure and task of EHB are different from those of ESP, and the simulation parameters are set up according to hydraulic control unit of BOSCH ESP 8.0.

Sectional area of high-speed solenoid valve directly affects change rate of brake cylinder pressure, as shown in Figure 14. Based on the above analysis, it is necessary to redesign sectional area of high-speed solenoid valve in order to reduce change rate of brake cylinder pressure effectively and meet the conventional braking requirement and emergency braking requirement simultaneously. Meanwhile, if sectional area of high-speed solenoid valve changes between 1.2 and 0.9 , variations in change rate of brake cylinder pressure are slight. This finding proves that change rate of brake cylinder pressure 


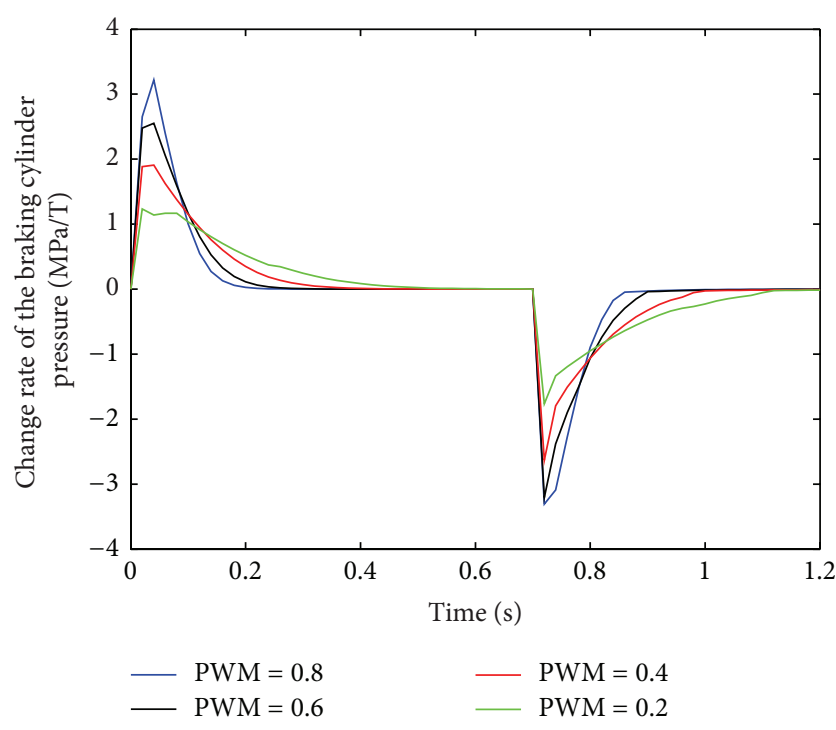

FIGURE 13: Relationship between the change rate of brake cylinder pressure and duty ratio of accumulator.

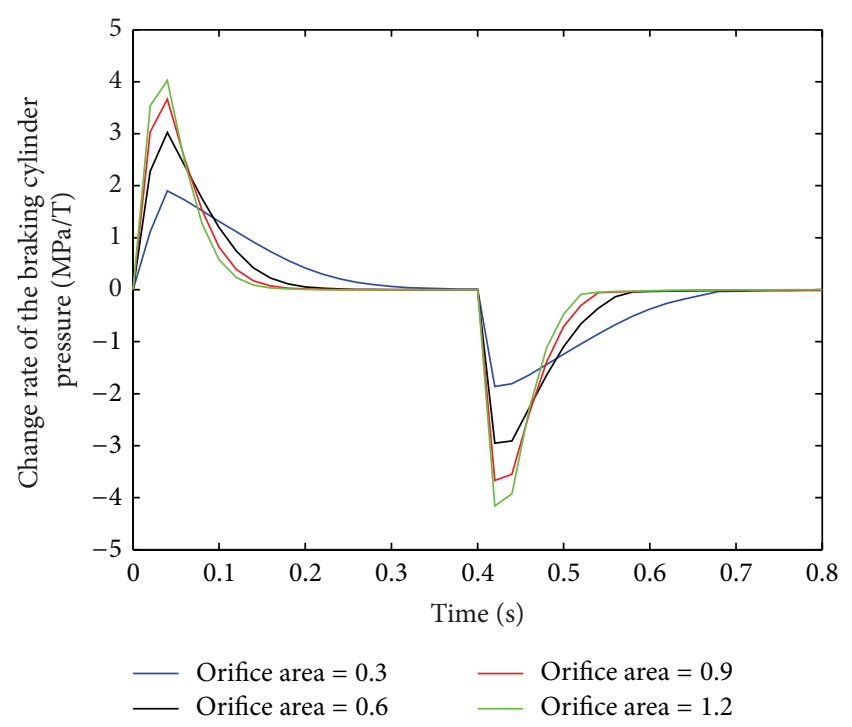

FIGURE 14: Relationship between change rate of brake cylinder pressure and sectional area of high-speed solenoid valve.

is of slight difference when the sectional area is relatively larger.

3.1.3. Static Error of Wheel Cylinder Pressure. The static error of wheel cylinder pressure refers to the ratio of volatile pressure value and set value of wheel cylinder pressure, which reflects the control precision of EHB. As is illustrated in Figure 15, the static error of wheel cylinder pressure reduces continuously with the increase of wheel cylinder pressure because the differential pressure reduces on both ends of high-speed solenoid valve according to (4). It is clear that the smaller the differential pressure becomes on both ends of high-speed solenoid valve, the more precise its control

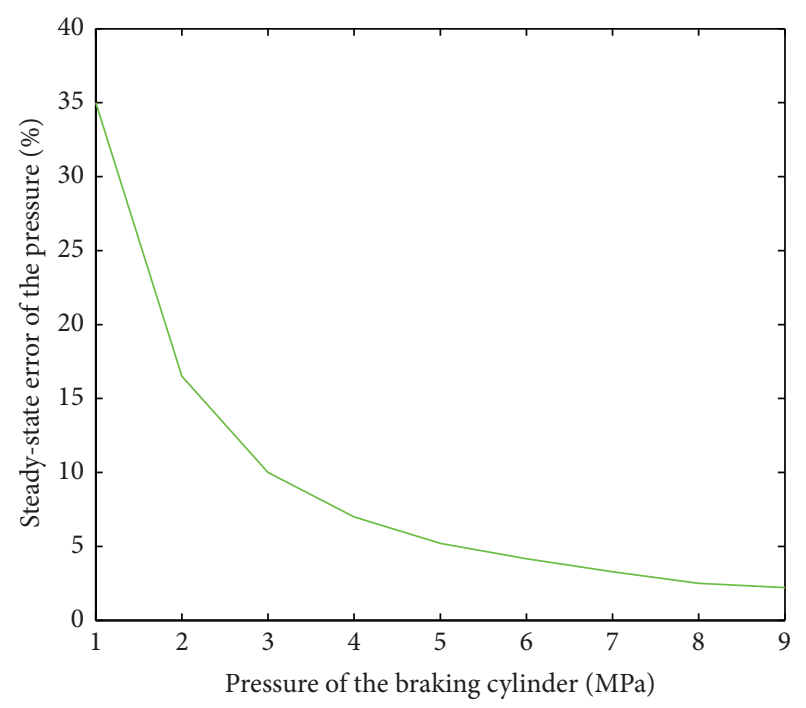

FIGURE 15: Relationship between steady-state error of the wheel cylinder pressure and wheel cylinder pressure.

would be under the same hardware condition. At the same time, it should be pointed out that the steady control accuracy of brake cylinder pressure is unsatisfactory for electronic hydraulic brake under the low intensity brake condition and the gas pressure of accumulator always stays higher than $12 \mathrm{Mpa}$. As a result, the balance between control precision in low intensity brake and brake response time in high intensity brake should be considered in the design of electronic hydraulic brake.

The relationship between natural frequency of highspeed solenoid valve and steady-state error of wheel cylinder pressure is clearly of physical significance. The higher the natural frequency of high-speed solenoid valve becomes (natural frequency indicates response time between valve opening and valve shutting), the higher the control precision of wheel cylinder pressure can be obtained. As is seen from Figure 16, the steady-state error of wheel cylinder pressure increases significantly when natural frequency of high-speed solenoid valve is lower than $100 \mathrm{~Hz}$ in this paper. The control precision of wheel cylinder pressure increases slightly when natural frequency is higher than $300 \mathrm{~Hz}$. Therefore, natural frequency of high-speed solenoid valve is selected as a factor of the design.

3.2. Dynamic Characteristics of ISEFB. To study the influence of EHB dynamic characteristics on the design and control strategy of ISEFB, three groups of simulation experiments are conducted. The simulating parameters of the integrated system are the same as that in the previous section and the influences of time delay and rotating speed of the electromagnetic brake are all neglected in this paper [27]. There are three braking modes of the integrated brake system: electromagnetic brake mode, friction brake mode, and united brake mode. The integrated braking system can switch between these three braking modes to realize different braking requirements. 


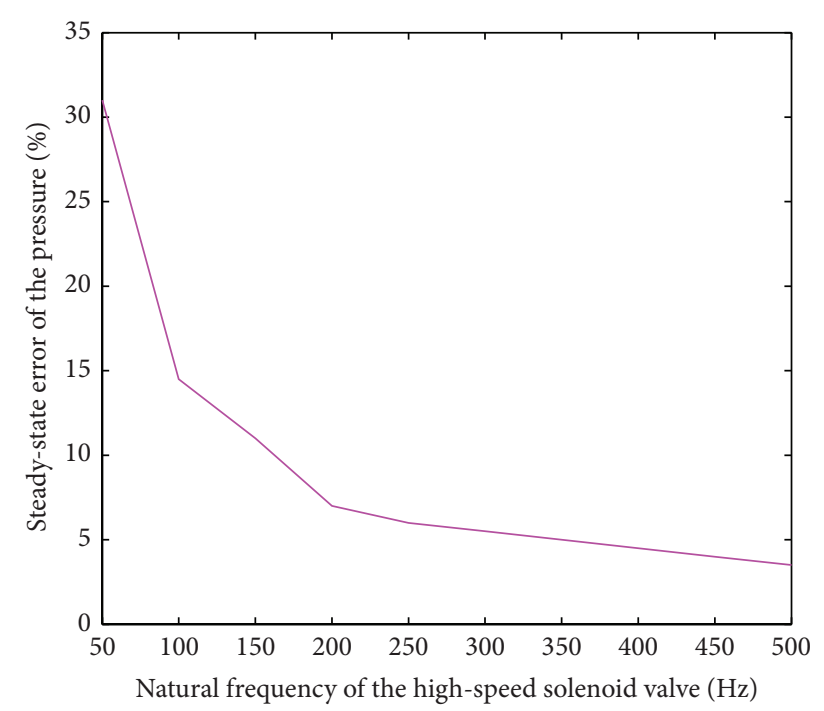

FIGURE 16: Relationship between steady-state error of the wheel cylinder pressure and natural frequency of high-speed solenoid valve.

In the first simulation experiment, maximum electromagnetic braking torque is $100 \mathrm{~N} \cdot \mathrm{m}$, and change rate of braking intensity is $0.05 \mathrm{~g} / \mathrm{s}$. To meet this requirement, the integrated braking system is switched to electromagnetic brake mode in the initial stage and the electromagnetic brake mode runs independently. At $0.124 \mathrm{~s}$, the integrated brake system then is switched to united brake mode through sending a pulse signal, duty ratio of which is 0.2 to inlet valve. As is shown in Figure 17, the dynamic control process can meet the requirements for change rate of braking intensity. It is obvious that the driver's braking sense will get worse if $\mathrm{EHB}$ is used alone for braking. In the redesign of $\mathrm{EHB}$, researchers should fully consider reducing change rate of brake cylinder pressure and natural frequency of high-speed solenoid valve for better braking effects.

Another two groups of simulation experiments will be explained later. Simulation experiments 1 and 2 are carried out, as shown in Figures 18(a) and 18(b), and the maximum electromagnetic braking torques of experiments 1 and 2 are $200 \mathrm{~N} \cdot \mathrm{m}$ and $100 \mathrm{~N} \cdot \mathrm{m}$, respectively. In simulation experiment 1, ECU sends a pulse signal (duty ratio is 0.2 ) to outlet valve at $0.64 \mathrm{~s}$, and then the brake mode is switched from original electromagnetic mode to united brake mode. Subsequently, ECU sends another pulse signal (duty ratio is 0.2 ) to outlet valve at $1.9 \mathrm{~s}$. Unlike simulation experiment $1, \mathrm{ECU}$ sends a pulse signal (duty ratio is 0.2 ) to inlet valve at $1.22 \mathrm{~s}$ in simulation experiment 2 and then sends another pulse signal (duty ratio is 0.5 ) to outlet valve of EHB. These two simulation experiments both meet the requirements for change rate of braking intensity, and their differences lie in the frequency of high-speed solenoid valve actuations: 2 times in simulation experiment 1 and 3 times in simulation experiment 2 . In addition, braking overshoot of simulation experiment 2 is greater than that of simulation experiment 1 . By comparing two simulation experiments, the conclusion can be made: The larger the adjusting range of electromagnetic braking torque

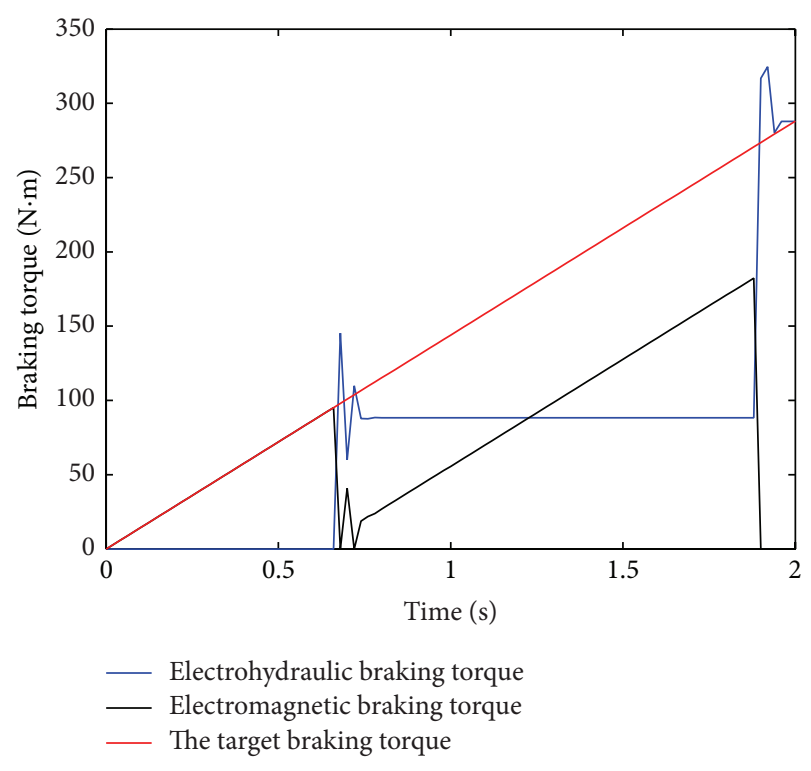

FIGURE 17: Dynamic booster process at $0.05 \mathrm{~g} / \mathrm{s}$ braking rate.

is, the more specific the design target for natural frequency and use frequency of high-speed solenoid valve will be.

\section{Analysis and Discussion}

4.1. Design of Integrated System of Electromagnetic Brake and Frictional Brake. For vehicles equipped with EHB alone, it would be a challenge to meet both conventional braking requirement and emergency braking demand. Therefore, there are two significant factors to be considered in the design of the system: response speed and control precision. Meanwhile, the failure security of hardware and software [28] and the reliability of high-speed solenoid valve, hydraulic pump, and the drive motor should be all checked.

In the integrated system of electromagnetic brake and frictional brake, it is unnecessary for EHB to fulfill both functions of response speed and control precision. The objectives of the ISEFB design can be divided into the minimum and the maximum change rate of brake cylinder pressure, which indicates the possibility of rapid pressurization and rapid depressurization in emergency braking as well as that of adjusting electromagnetic braking torque range. In the conventional braking condition, EHB is only equipped with enough pressure and accumulator volume to ensure the safety of automobile brake system. However, in the integrated brake system, the minimum/maximum change rate of brake cylinder pressure and the adjusting range of electromagnetic braking torque should match each other in the design so that various braking requirements can be met. In the emergency braking condition, EHB can rapidly get pressurized or depressurized with the maximum change rate of brake cylinder pressure; besides, braking characteristics of electromagnetic brake manage to control the wheel slip ratio because the electromagnetic brake has advantages such as fast response and simple control. 


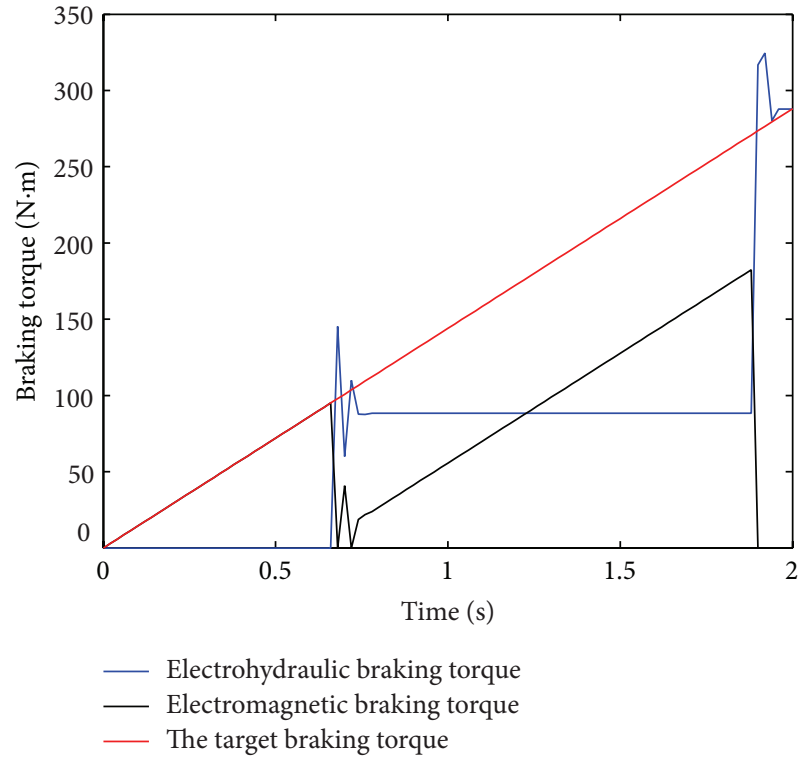

(a)

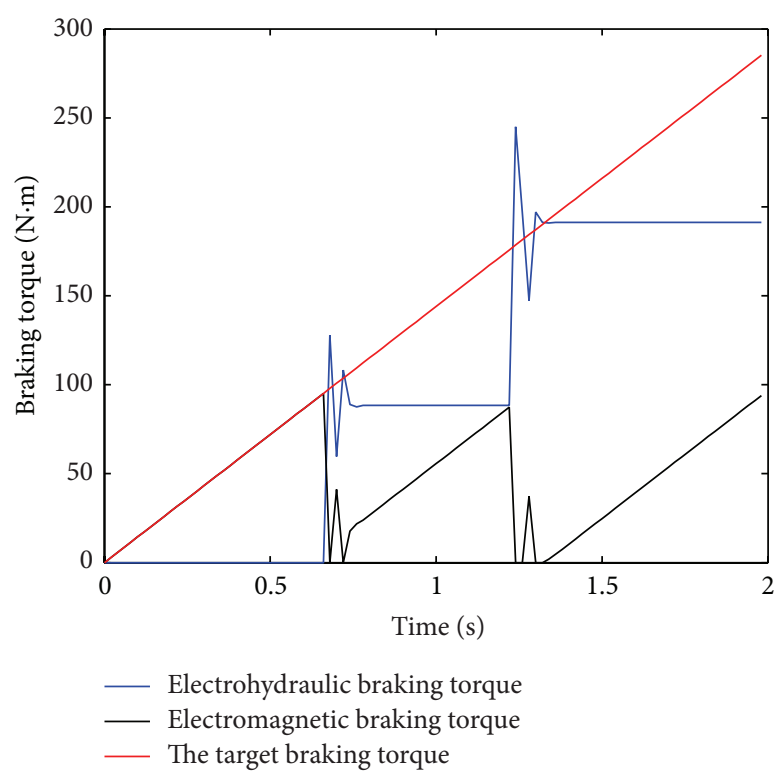

(b)

FIGURE 18: Dynamic booster processes at $0.05 \mathrm{~g} / \mathrm{s}$ braking rate.

The adjusting range of electromagnetic braking torque should be wider based on the previous section. When the adjustment range of electromagnetic braking torque becomes wider, response time of electronic hydraulic brake system will be less and the corresponding requirement for control accuracy will be lower. At the same time, natural frequency of high-speed solenoid valve for EHB will be reduced to ensure the reliability of EHB. However, the braking torque of electromagnetic brake should be controlled within an optimal range because the wider adjusting range of braking torque causes bigger volume and heavier weight of electromagnetic brake, which increases the automotive unsprung mass and energy consumption [29].

4.2. Control Strategy of ISEFB under the Emergency Brake. The vehicle braking system is mainly controlled by EMB, and EHB is generally started in emergency brake condition. In emergency braking, electromagnetic brake starts first and then electronic hydraulic brake system gets pressurized simultaneously. In this process, response time of car is reduced when the car is running on the high adhesion road. Controller is used to detect the wheel lock. If the wheel lock tendency cannot be prevented, EHB continues getting pressurized until wheel lock is excluded. In case of wheel lock, electromagnetic braking torque is adjusted to avoid locking [30]. What if the increase or decrease of braking torque of electromagnetic brake reaches a certain threshold but the tendency of wheel lock is obvious? For example, the down threshold and the up threshold are, respectively, $20 \%$ and $80 \%$ of electromagnetic braking torque. In this situation, EHB is used to increase or decrease the pressure if the trend of the wheel lock is still not improved.

\section{Conclusion}

In this paper, ISEFB's nonlinear coupling mathematical model is established and verified on the hardware in the loop simulation platform. The nonlinear coupling and dynamic characteristics of the ISEFB are analyzed.

Some conclusions are reached as follows: There exists a nonlinear coupling relationship between EMB and EHB only when the rotation speed of brake disc is within a certain range. It is a complex and challenging work to solve the conflict between conventional brake requirement and emergency brake demand in the design of EHB. If adjusting range of electromagnetic braking torque is wider, braking response time will be less and the control accuracy requirement of EHB will be correspondingly reduced in the ISEFB. The working frequency of EHB's high-speed solenoid valve would be reduced effectively in ISEFB if EHB is used for the driver's braking intensity and electromagnetic brake is employed to track the change rate of the demanded braking intensity.

The main contributions of the paper are as follows: (1) the nonlinear coupling mathematical model of the ISEFB is established and it provides the theoretical foundation for its decoupling control; (2) the analysis of dynamic characteristics of EHB in this study brings new ideas for its design and control so that the usability and failure security of EHB can be optimized; (3) this paper also points out that ISEFB can be used to replace the traditional antilock brake system when hydraulic brake subsystem fails in control accuracy by coordinated controlling EMB and EHB.

\section{Conflict of Interests}

The authors declare that there is no conflict of interests regarding the publication of this paper. 


\section{Acknowledgments}

This research was financially supported by the National Natural Science Foundation of China under Grant no. 51275212, the Priority Academic Program Development of Jiangsu Higher Education Institutions, 2014 Jiangsu Province Postgraduate Innovative Fund Project (KYLX, 1025), and 2013 Industrial Centre Students' Innovative Practice Fund (201302).

\section{References}

[1] S. M. Savaresi and M. Tanelli, Active Braking Control Systems Design for Vehicles, Advances in Industrial Control, Springer, London, UK, 2010.

[2] B. Breuer and K. H. Bill, Brake Technology Handbook, SAE International, 2008.

[3] W. Jonner, H. Winner, L. Dreilich, and E. Schunck, "Electrohydraulic brake system-the first approach to brake-by-wire technology," SAE Technical Paper 960991, 1996.

[4] B. Morey, "Continental focuses on faster braking with electrohydraulic system," Automotive Engineering International, vol. 120, no. 3, 2012.

[5] Z.-L. Jin, L.-S. Guo, Y.-Q. Zhao, and R.-K. Shi, "Research on Brake Pedal Emulator of vehicle with controllable pedal feeling," Journal of System Simulation, vol. 22, no. 12, pp. 2795-2798, 2010.

[6] L. Petruccelli, M. Velardocchia, and A. Sorniotti, "Electrohydraulic braking system modelling and simulation," SAE Technical Paper, 2003.

[7] K. Huh, K. Han, D. Hong et al., "A model-based fault diagnosis system for electro-hydraulic brake," SAE Technical Paper, SAE International, 2008.

[8] D. Hu, R. He, J. Yu et al., "Research of regenerative braking control strategy of electric vehicle based on electrohydraulic hybrid brake system," Journal of Highway and Transportation Research and Development, vol. 31, no. 3, pp. 148-152, 2014.

[9] Z. Jin, L. Guo, R. Shi, Y. Zhao, and Z. Shi, "Experimental study on dynamic characteristics of electro hydraulic brake system for vehicle," Journal of Mechanical Engineering, vol. 48, no. 12, pp. 127-132, 2012.

[10] K. Karakoc, A. Suleman, and E. J. Park, "Optimized braking torque generation capacity of an Eddy current brake with the application of time-varying magnetic fields," IEEE Transactions on Vehicular Technology, vol. 63, no. 4, pp. 1530-1538, 2014.

[11] A. Pernestål, M. Nyberg, and H. Warnquist, "Modeling and inference for troubleshooting with interventions applied to a heavy truck auxiliary braking system," Engineering Applications of Artificial Intelligence, vol. 25, no. 4, pp. 705-719, 2012.

[12] K. Lee and K. Park, "Optimal robust control of a contactless brake system using an eddy current," Mechatronics, vol. 9, no. 6, pp. 615-631, 1999.

[13] S. Anwar, "Generalized predictive control of yaw dynamics of a hybrid brake-by-wire equipped vehicle," Mechatronics, vol. 15, no. 9, pp. 1089-1108, 2005.

[14] S. Anwar, "A parametric model of an eddy current electric machine for automotive braking applications," IEEE Transactions on Control Systems Technology, vol. 12, no. 3, pp. 422-427, 2004.

[15] M.-M. Zhang, L. Chen, Y. Huo, X.-P. Xie, and S. Lu, "Model reduction of high speed on-off solenoid valve and experimental validation," Journal of Shanghai Jiaotong University, vol. 44, no. 7, pp. 1005-1009, 2010.

[16] Y. Zhang, Studies on Matching Process and Calibration Technologies of ABS, Tsinghua University, Beijing, China, 2010.

[17] B. Jiao, D. Li, X. Du, and K. Zhang, "Performance analysis and experimentation of a liquid-cooled eddy current retarder with a dual salient poles design," IEEE Transactions on Energy Conversion, vol. 29, no. 1, pp. 84-90, 2014.

[18] D. Hu and R. He, "Calculation method of braking torque for eddy current brake based on virtual coil assumptions," Journal of Jiangsu University (Natural Science Edition), vol. 35, no. 3, pp. 257-261, 2014.

[19] S. Anwar and R. C. Stevenson, "Torque characteristics analysis for optimal design of a copper-layered eddy current brake system," International Journal of Automotive Technology, vol. 12, no. 4, pp. 497-502, 2011.

[20] H. Jing, Z. Liu, and H. Chen, "A switched control strategy for antilock braking system with on/off valves," IEEE Transactions on Vehicular Technology, vol. 60, no. 4, pp. 1470-1484, 2011.

[21] Y. H. Ki, K. J. Lee, J. S. Cheon, and H. S. Ahn, "Design and implementation of a new clamping force estimator in ElectroMechanical Brake systems," International Journal of Automotive Technology, vol. 14, no. 5, pp. 739-745, 2013.

[22] K. J. Lee, Y. H. Ki, J. S. Cheon, G. Hwang, and H. S. Ahn, "Approach to functional safety-compliant ECU design for electro-mechanical brake systems," International Journal of Automotive Technology, vol. 15, no. 2, pp. 325-332, 2014.

[23] R. He, X. Liu, and C. Liu, "Brake performance analysis of ABS for eddy current and electrohydraulic hybrid brake system," Mathematical Problems in Engineering, vol. 2013, Article ID 979384, 11 pages, 2013.

[24] J. Han and Y. Park, "Cooperative regenerative braking control for front-wheel-drive hybrid electric vehicle based on adaptive regenerative brake torque optimization using under-steer index," International Journal of Automotive Technology, vol. 15, no. 6, pp. 989-1000, 2014.

[25] J. Song, "Integrated control of brake pressure and rear-wheel steering to improve lateral stability with fuzzy logic," International Journal of Automotive Technology, vol. 13, no. 4, pp. 563570, 2012.

[26] Z. Xu, M.-X. Wei, and Y.-F. Li, "Variation characteristic of wheel cylinder pressure in electro-hydraulic braking system controlled by PWM signal," Journal of Traffic and Transportation Engineering, vol. 13, no. 1, pp. 55-61, 2013.

[27] M. O. Gulbahce, D. A. Kocabas, and A. K. Atalay, "Determination of the effect of conductive disk thickness on braking torque for a low power eddy current brake," in Proceedings of the 4th International Conference on Power Engineering, Energy and Electrical Drives (POWERENG '13), pp. 1272-1276, May 2013.

[28] D. F. Reuter, E. W. Lloyd, J. W. Zehnder et al., "Hydraulic design considerations for EHB systems," SAE Technical Paper, 2003.

[29] C. Y. Liu, K. J. Jiang, and Y. Zhang, "Design and use of an eddy current retarder in an automobile," International Journal of Automotive Technology, vol. 12, no. 4, pp. 611-616, 2011.

[30] X. Liu and R. He, "Sliding mode control in electromagnetichydraulic hybrid anti-lock braking system," Transactions of the Chinese Society for Agricultural Machinery, vol. 45, no. 5, pp. 1-7, 2014. 


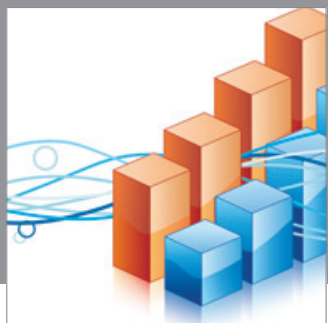

Advances in

Operations Research

mansans

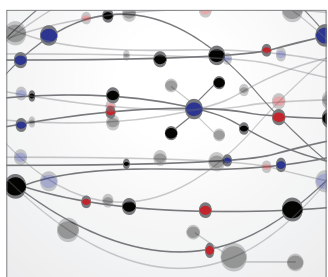

The Scientific World Journal
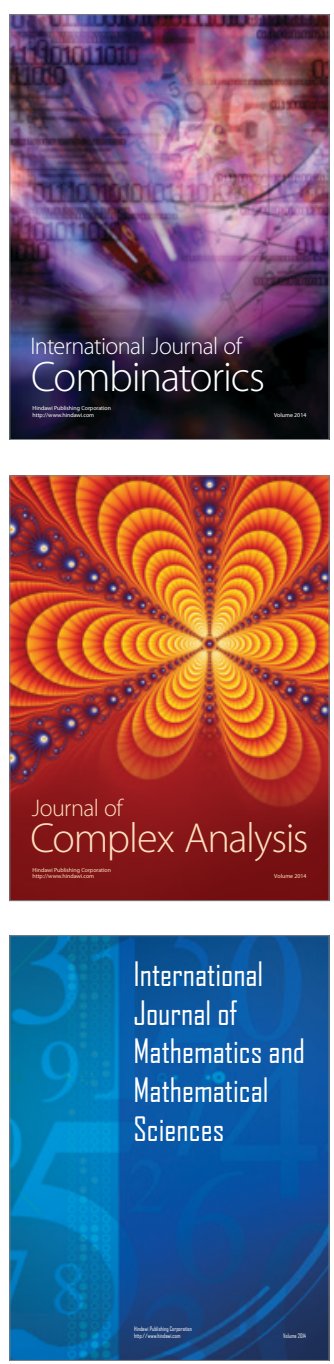
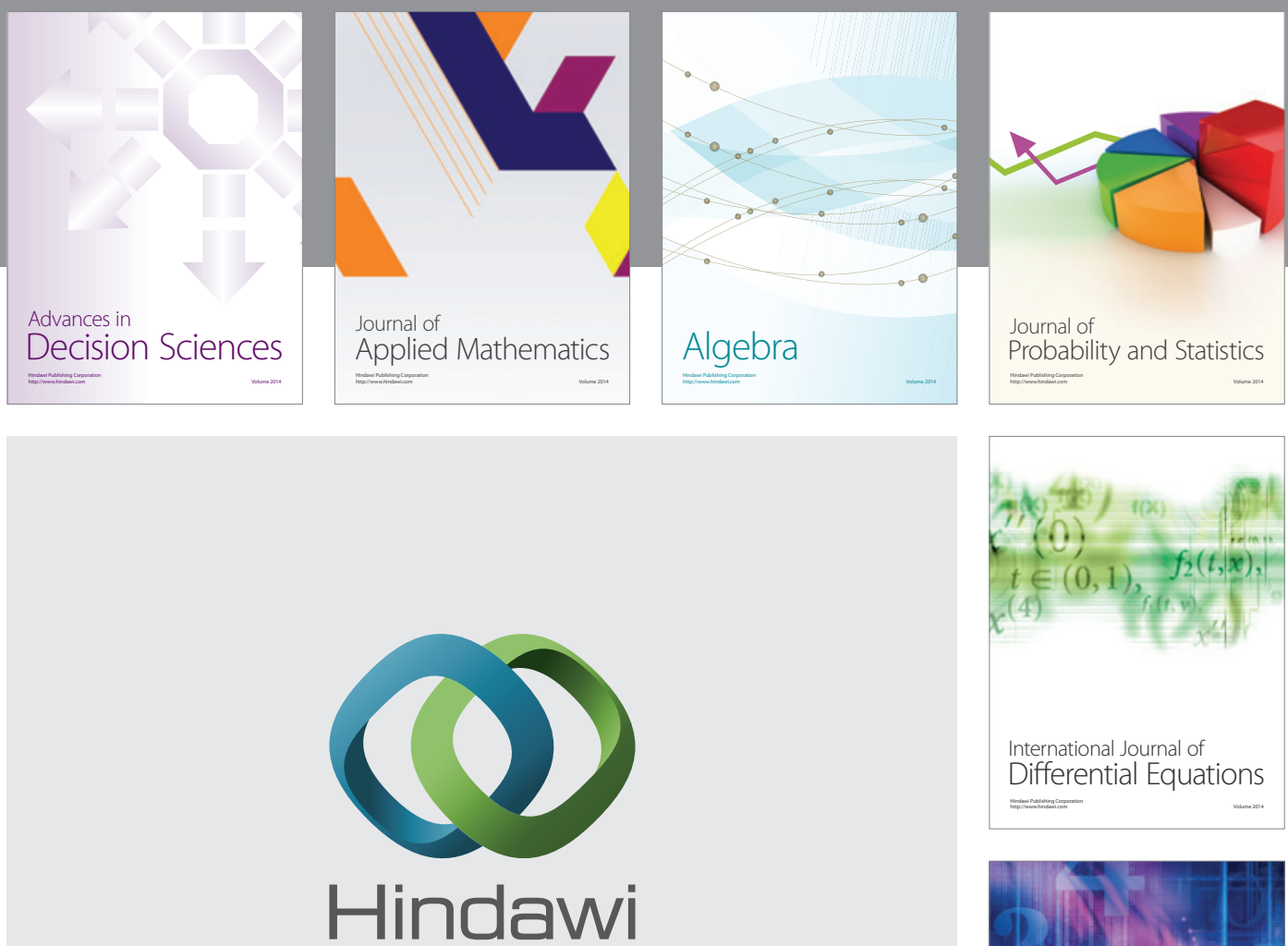

Submit your manuscripts at http://www.hindawi.com
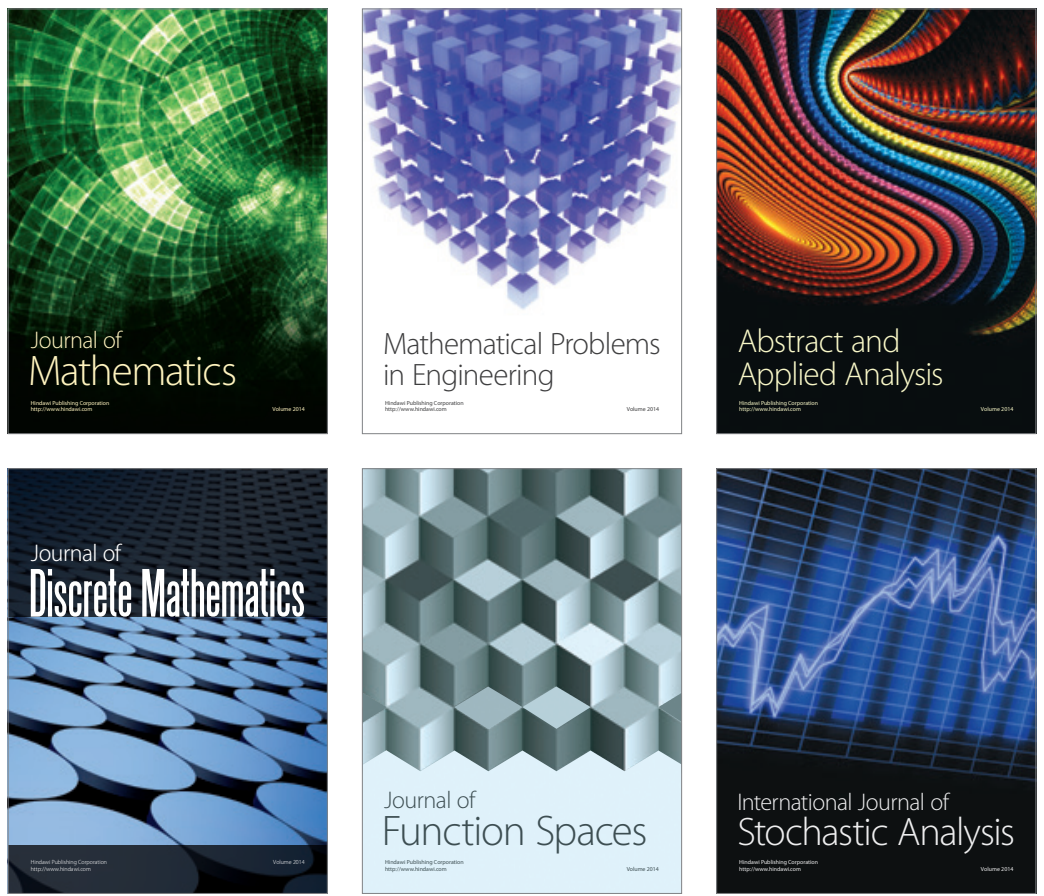

Journal of

Function Spaces

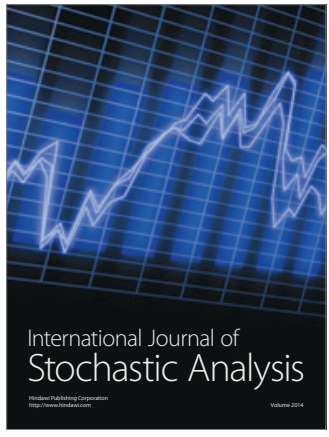

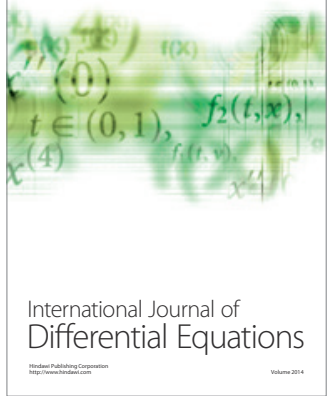
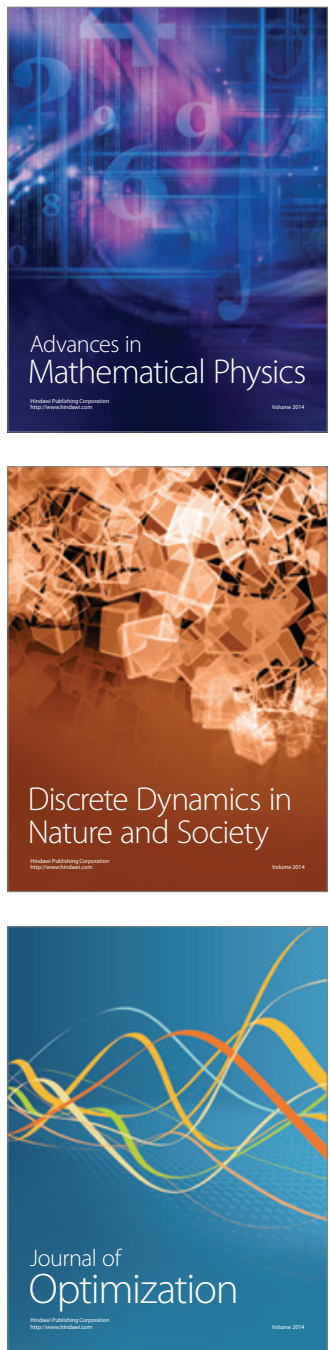